Review Article

\title{
A Review on Properties, Opportunities, and Challenges of Transformer Oil-Based Nanofluids
}

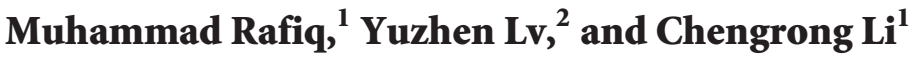 \\ ${ }^{1}$ Beijing Key Laboratory of High Voltage \& EMC, North China Electric Power University, Beijing 102200, China \\ ${ }^{2}$ School of Energy, Power and Mechanical Engineering, North China Electric Power University, Beijing 102200, China
}

Correspondence should be addressed to Muhammad Rafiq; jutt96@gmail.com

Received 23 December 2015; Revised 9 May 2016; Accepted 17 May 2016

Academic Editor: Paulo Cesar Morais

Copyright (C) 2016 Muhammad Rafiq et al. This is an open access article distributed under the Creative Commons Attribution License, which permits unrestricted use, distribution, and reproduction in any medium, provided the original work is properly cited.

\begin{abstract}
The mineral oil or synthetic oil in conjunction with paper is mainly being applied as dielectric medium in many of the high voltage apparatus. However, the advent of high voltage levels such high voltage alternating current (HVAC) and high voltage direct current (HVDC) has prompted researchers to direct their focus onto an insulation system which can bear the rising high voltage levels. The modern insulating liquid material development is guided by various factors such as high electrical insulation requirements and other safety and economic considerations. Therefore transformer manufacturer companies have to design transformers with these new specific requirements. The transformer oil-based nanofluids with improved dielectric and thermal properties have the potential to replace mineral oil base products in the market place. They are favorable because they function more superior than mineral oil and they contribute definite insulating and thermal gains. This paper reviews recent status of nanofluids use as transformer oils. The nanofluids used as transformer oils are presented and their advantages are described in comparison with mineral oil. The multiple experimental works carried out by different researchers are described, providing an overview of the current research conducted on nanofluids. In addition scope and challenges being confronted in this area of research are clearly presented.
\end{abstract}

\section{Introduction}

The development of future high voltage network and smart grid has elevated high demands on the reliability and performance of insulating materials used in electric power system to deal with more dynamic and volatile operating conditions [1]. A transformer, which transforms voltage and transfer energy, is the most critical part of an electric power network. A potential result of transformer failure can be seriously destructive [2]. Most of the transformers in operation around the world are close to or beyond their design life; therefore, it has been a prime focus on the working reliability of these existent units [3]. The available transformer failure statistics acknowledge that the typical service life of transformers which failed because of insulation problems is 17.8 years, which is almost half of the expected life of 35 to 40 years [3], and $75 \%$ of high voltage transformers collapse was originated by dielectric insulation issues [4]. The operational reliability and lifetime of transformers primarily rely on traits and status of insulation material [5-7].
Mineral oils have been used as insulating and coolant material for almost over a century in transformers due to their thermal and insulating features [8]. To cope with the increasing demand of high voltage rate and small size for transformers, the development of transformer oil with favorable dielectric and thermal characteristics is extensively required [9-11]. Therefore, dielectric nanofluids have been produced to meet the above mentioned necessary attributes.

Nanofluids, a well known and a prominent term nowadays in dielectric society, have been the subject of huge research work over the past decade. In fact, the term "nanofluid" was first presented by Choi at Argonne National Laboratory of the USA in 1995 [12]. A liquid with nanosized particles homogeneously suspended at just a few weight percentage (wt\%) is called nanofluid or nanoliquid. However, for the scope of high voltage liquid electrical insulation research, the terms "nanofluids" and "nano-liquids" are used mutually to refer to transformer oil/nanoparticle combination for insulating and cooling interest. 
Nanodielectric has gained a remarkable attention due to recent progress in nanotechnology after its first conceptual introduction in the 1990s $[13,14]$. The research work has manifested that addition of nanomaterials effectively improves the insulation life of solid polymers. The same approach was also applied for dielectric liquid insulation to enhance its dielectric and thermal characteristics. These materials are developed by suspension of nanosized particles into transformer oil, with the aim of enhancing insulating and cooling properties of oil. The experimental results of nanofluids reported enhanced thermal [15-19] and insulating properties [20-23]. However, initially conventional micronsized particles were employed in these liquids for thermal conductivity enhancement [24]. The major disadvantage attached with fluids containing micron-sized particles was the subsequent decrease in dielectric strength [25]. Another disadvantage connected with micron-sized particles was that they have the tendency to rapidly fall out of the suspension under density because their density is most often larger than the density of the continuous phase in which they were added.

Why Nanofluids? The trend toward nanofluids research cropped up from the rising requirement of electrical engineers to develop modern electric insulation systems that have the capability and capacity to withstand high voltage levels, for example, for $\mathrm{HV}$ alternating current (HVAC) and $\mathrm{HV}$ direct current (HVDC) applications. Even though HVAC has been used around the world since the 1880s whereas HVDC transmission systems were evolved in the 1950s because of their potential to cope with many problems (dynamic and steady state issues) relevant to the interconnection with HVAC power system for long distances [49], therefore, a lot of HVDC transmission systems are in use and considered as vital part of electric networks around the globe [50]. Both AC and DC voltage levels are expected to rise further to meet the ever increasing demand of electric power worldwide.

Unluckily, the current electrical insulation system in use comes with the compromise of restricted electrical performance, as a consequence of the demand to address thermal, economic, and mechanical concerns. For instance, to develop thermally efficient insulation system, microsized particles were added to the conventional liquid insulation to obtain a combination of characteristics that reflects both the particles and liquid insulation. The incorporation of microsized particles, despite enhancing thermal properties such as cooling and thermal conductivity, introduces more defects into overall insulation system [25].

By contrast, the suspension of nanoparticles to conventional liquid insulation is expected to be capable of improving the insulating properties of insulation systems while considering thermal and economic requisites thus reducing the above mentioned compromise. It is supposed to be associated with the smaller size of the nanoparticles which subsequently leads to the existence of large interfacial area-an interaction zone between the nanoparticle and the oil. In this regard, nanofluids are expected to have distinct dielectric characteristics which highly differ from previous traditional microfluids. Such unique characteristics improvement brought about by nanodevelopment have led to suggestion that this could be a new class of fluids that dielectric community has been looking for (dielectric fluids with combined electrical, thermal improvements), as this would be an exceptional class of fluids for AC and DC application. In reality, a lot of research projects were initiated to look into potentials and prospectus of developing nanofluids for next generation ultrahigh voltage AC and DC power transmission systems.

In recent years, nanofluids have attracted more and more attention because of their excellent and unique characteristics. Although some review articles on the thermal properties of nanofluids have been published in recent years it would seem that no review presented combined thermalphysical and electrical properties. This review not only provides insight of insulating and thermal characteristics of transformer oil-based nanofluids but also provides comprehensive details of recent challenges and future opportunities in transformer oil-based nanofluids. In addition, it gives an overview of the advantages, disadvantages, and potential application of transformer oil-based nanofluids.

\section{Experimental and Promising Key Findings}

\subsection{Experimental}

2.1.1. Material Selection. The selection of nanoparticles which are suitable for improvement of dielectric properties of transformer oil is hugely challenging. Normally, nanoparticles are chosen by looking at their basic properties such as conductivity and permittivity. A huge number of nanoparticles have been examined with the goal to enhance dielectric characteristics of liquid insulation [34-36, 43-46, 51-58]. These nanoparticles can be categorized into following classification, namely, conductive nanoparticles $\left(\mathrm{Fe}_{3} \mathrm{O}_{4}, \mathrm{ZnO}\right.$, and $\left.\mathrm{SiC}\right)$, insulative nanoparticles $\left(\mathrm{SiO}_{2}, \mathrm{Al}_{2} \mathrm{O}_{3}\right)$, and semiconductive nanoparticles $\left(\mathrm{TiO}_{2}, \mathrm{CuO}\right.$, and $\left.\mathrm{Cu}_{2} \mathrm{O}\right)$. The carrier oils are normally mineral or vegetable oils. The basic properties of some of the nanoparticles are listed in Table 1.

2.1.2. Preparation of Nanofluids. The first foot-step for experimentation is the preparation of nanofluids. Generally, there are two methods of preparation of transformer oil-based nanofluids which can be categorized as one-step and twostep methods. A brief introduction on preparation processes is given as follows.

(1) Single-Step Method. In the one-step method, the nanoparticles are developed and suspended in the base liquid at the same time; that is, the course of drying, storage, and conveyance of nanoparticles is by-passed with the intention to diminish the agglomeration and the stability of nanoparticles suspension is enhanced $[59,60]$. The disadvantages associated with one-step method are their high cost and problems with a large scale production.

(2) Two-Step Method. For a two-step method, the solid nanoparticles are prepared (either by physical or by chemical methods) and then suspended in the carrier oil ultrasonic route, magnetic stirring, high-shear mixing, or ball milling. This method is broadly employed to produce nanofluids on 
TABLE 1: Basic properties of conducting, insulating, and semiconducting nanoparticles [26].

\begin{tabular}{lcccccc}
\hline & $\begin{array}{c}\text { Magnetite } \\
\left(\mathrm{Fe}_{3} \mathrm{O}_{4}\right)\end{array}$ & $\begin{array}{c}\text { Zinc oxide } \\
(\mathrm{ZnO})\end{array}$ & $\begin{array}{c}\text { Alumina } \\
\left(\mathrm{Al}_{2} \mathrm{O}_{3}\right)\end{array}$ & $\begin{array}{c}\text { Quartz } \\
\left(\mathrm{SiO}_{2}\right)\end{array}$ & $\begin{array}{c}\text { Silica } \\
\left(\mathrm{SiO}_{2}\right)\end{array}$ & $\begin{array}{c}\text { Titania } \\
\left(\mathrm{TiO}_{2}\right)\end{array}$ \\
\hline Density $\left(\mathrm{g} / \mathrm{cm}^{3}\right)$ & 5.17 & 5.61 & 3.96 & 2.65 & 2.20 & $4.2-4.3$ \\
Electric conductivity $(\mathrm{S} / \mathrm{m})$ & $1 \times 10^{4}-1 \times 10^{5}$ & $10-1 \times 10^{3}$ & $1 \times 10^{-12}$ & $1.3 \times 10^{-18}$ & $1.4 \times 10^{-9}$ & $1 \times 10^{-11}$ \\
Relative dielectric constant & 80 & $7.4-8.9$ & 9.9 & $3.8-5.4$ & 3.8 & 100 \\
Relaxation time constant $(\mathrm{s})$ & $7.47 \times 10^{-14}$ & $1.05 \times 10^{-11}$ & 12.2 & 36.3 & $5.12 \times 10^{-2}$ & 77 \\
Thermal conductivity $\left(\mathrm{W} \mathrm{m}^{-1} \mathrm{~K}^{-1}\right)$ & $4-8$ & 23.4 & 30 & 11.1 & 1.4 & - \\
Thermal expansion coefficient & 9.2 & 2.9 & - & 8.1 & 30 & - \\
at $20^{\circ} \mathrm{C}\left(\mu \mathrm{m} \mathrm{m}^{-1} \mathrm{~K}^{-1}\right)$ & - & 494 & 850 & - & 670 & - \\
Specific heat $\left(\mathrm{J} \mathrm{kg}^{-1} \mathrm{~K}^{-1}\right)$ & & & & & - & \\
\hline
\end{tabular}

a large scale because of its lower cost [20-22]. Nevertheless, there are high chances of agglomeration of nanoparticles during both stages of two-step method due to a huge surface area and the large surface activity of the nanoparticles [38]. The most common two-step process is elaborated in Figure 1.

2.2. Key Findings and Outlook. The promising application of nanofluids as insulation liquid was stimulated by Segal et al. [22] in 1998. A new class of colloidal fluid was prepared by dispersing magnetic nanoparticles into mineral oil with the aim to enhance its dielectric performance. In their investigation, several findings were concluded, such as (1) at certain optimal composition the AC breakdown voltage was almost the same at low moisture level but at higher moisture level the AC breakdown voltage was higher than the carrier oil; (2) the positive impulse breakdown voltages were increased for almost $50 \%$ as compared to the base oil with needle to sphere geometry; (3) the negative impulse breakdown voltages were close to the base mineral oil. This experiment attracted the attention of worldwide researchers toward nanofluids as insulation liquid.

Subsequent experimental work on nanofluids in electrical insulation applications was highly positive. Various nanofluids suspended with conductive [22], semiconductive [46, 61], and insulative nanoparticles were investigated and it was reported that the basic properties of nanoparticles such as electrical conductivity and permittivity significantly affect the dielectric performance of the colloid. Transformer oilbased nanofluid suspended with conductive nanoparticles improved the dielectric strength as compared to the carrier oil. However, the agglomeration of conductive nanoparticles caused serious problems. Researchers have therefore looked for other options like semiconducting and insulating nanoparticles to avoid aggregation problems $[5,37,62,63]$.

In the following sections, some of the recent research findings about nanofluids are presented.

\subsubsection{Electrical Properties}

(1) AC Breakdown Strength. The most essential and significant perquisite for an insulation liquid is AC breakdown voltage, which can be defined as the value of applied AC voltage at which disruptive discharge is initiated in the liquid. A number of test methods are usually employed in which a small amount of insulating liquid is exposed to an almost homogenous electric field between two electrodes dipped in insulation fluid. The voltage is increased until breakdown occurs. The IEC 60156 standard test is normally used with a gap of $2.5 \mathrm{~mm}$ and voltage rise rate of $2.5 \mathrm{kV} / \mathrm{s}$ [64]. The AC breakdown test is significantly influenced by impurities in the insulating liquid, such as small particles, moisture, and air or gas bubbles. Therefore, the measured AC breakdown voltage of an insulating liquid mainly indicates the oil quality rather than oil properties itself. A lot of researchers measured the AC breakdown strength of prepared nanofluids. In the following section the AC breakdown voltage results with respect to different parameters like moisture, nanoparticles type, concentration, and surface modification are presented.

(a) Factors Affecting AC Breakdown Strength. The experimental studies have shown that AC breakdown strength is affected by factors such as moisture, nanoparticle type, nanoparticle volume concentration, and surface modification of nanoparticles. In the following section, experimental studies about AC breakdown strength of transformer oil-based nanofluids are presented.

(i) AC Breakdown Strength and Moisture. The water content significantly affects the AC breakdown strength of insulating liquid. It can be found in two forms in insulating liquid as free water or dissolved water. The researchers have carried out experiments to see the effect of moisture on breakdown strength of insulation liquid [22, 41, 42]. Segal et al. [22] prepared $\mathrm{Fe}_{3} \mathrm{O}_{4}$ conductive mineral oil-based nanofluids. They measured AC breakdown voltages of prepared samples in accordance with ASTM D877 standard. They studied the effect of moisture on the breakdown strength of ferrofluid and oil carrier (Univolt 60 Exxon). They observed that AC breakdown strength of both oil and nanofluid decreases when the water content increases but ferrofluid indicated less dependence of its AC breakdown strength on the moisture than the oil (Figure 2). The authors concluded that this might be because of the dissolved water bound to the surface of nanoparticle. As it is known that multimolecular water clusters decrease the breakdown strength of insulating liquid, it was deduced that some multimolecular water clusters might be broken into single water molecules in nanofluids which might be attached to the surface of some nanoparticles [38, 


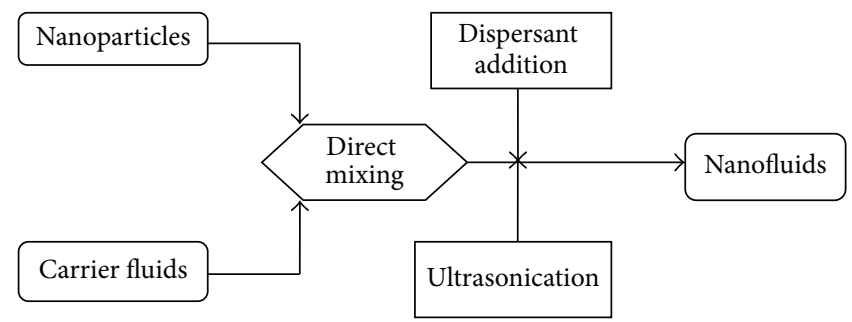

FIgURE 1: Two-step method for preparation of nanofluids.

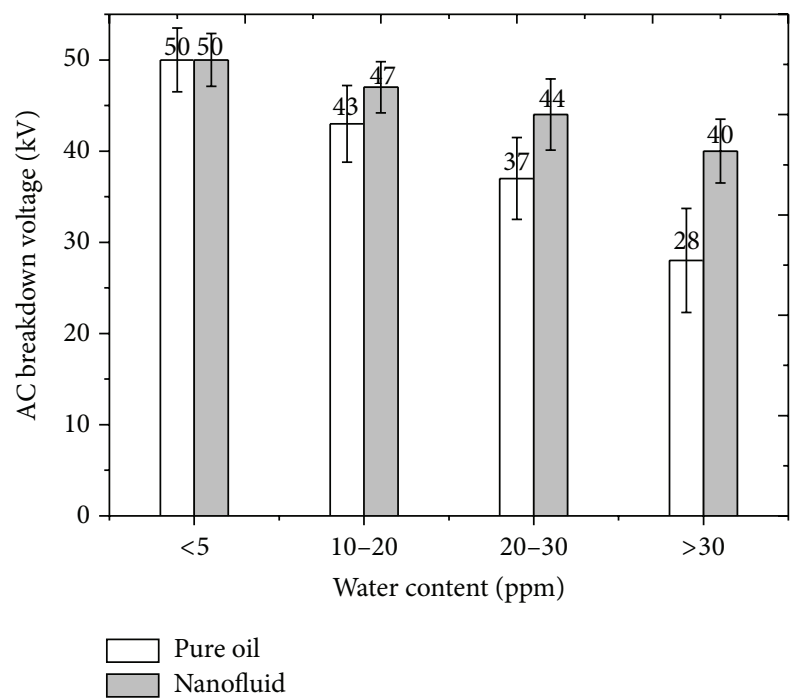

FIgURE 2: AC breakdown performance for pure oil and $\mathrm{Fe}_{3} \mathrm{O}_{4}$ nanofluids, as functions of the moisture content of the oil [22].

65], and the breakdown performance might be enhanced in the presence of nanoparticles.

$\mathrm{Du}$ et al. [41] measured the AC breakdown strength of mineral oil and nanofluids consisting of semiconducting $\mathrm{TiO}_{2}$ nanoparticles $(0.075 \mathrm{vol} \%)$ at a specific relative humidity range $(10 \%$ to $80 \%)$. They measured the $\mathrm{AC}$ breakdown strength of mineral oil and mineral oil modified by $\mathrm{TiO}_{2}$ nanoparticles in accordance with ASTM D1816 standard. The authors observed that the transformer oil-based nanofluids with $\mathrm{TiO}_{2}$ nanoparticles exhibited higher AC breakdown voltage as compared to base mineral oil at a high relative humidity (Figure 3). The authors concluded that semiconducting $\mathrm{TiO}_{2}$ nanoparticles decreased the distortion field produced by moisture content, leading to enhanced AC breakdown voltages for nanofluids as compared to pure oil.

Jin et al. [42] investigated AC breakdown strength of mineral oil and corresponding $\mathrm{SiO}_{2}$ nanofluids with $0.01 \%$ and $0.02 \%$ nanoparticle concentrations at two different humidity levels as shown in Figure 4. The results manifested improved AC breakdown strength for silica nanofluids, especially at higher moisture level. It shows that influence of silica nanoparticles on the breakdown voltage of mineral oil is more obvious when the moisture content is higher. The authors
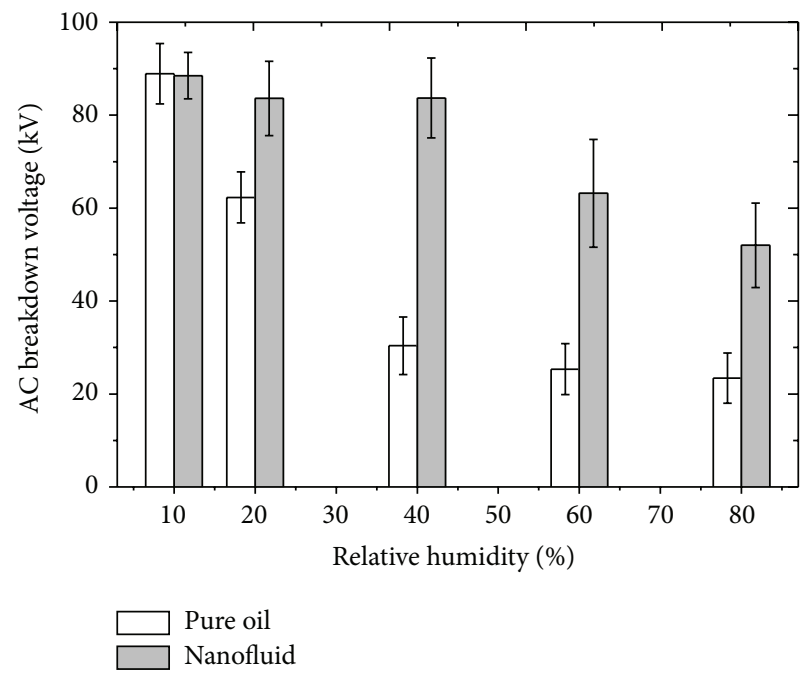

FIGURE 3: AC breakdown voltages for $\mathrm{TiO}_{2}$ nanofluids and pure oil, as functions of relative humidity (\%) [41].

attributed this enhancement by saying that the surface of $\mathrm{SiO}_{2}$ nanoparticles is hydrophilic, so it can bind water dispersed in oil on its surface. This could be the reason why moisture content could have less effect on the breakdown voltages of nanofluids than it has on mineral oil. Also, the surface of $\mathrm{SiO}_{2}$ nanoparticles can turn into conductive when water is absorbed.

(ii) Nanoparticle Concentration. Du et al. [43] studied the AC breakdown strength of mineral oil and corresponding $\mathrm{TiO}_{2}$ (rutile average particle size $d<20 \mathrm{~nm}$ ) nanofluids with different concentration of nanoparticles $(0.003 \mathrm{~g} / \mathrm{L}$ to $0.05 \mathrm{~g} / \mathrm{L})$ as shown in Figure 5. The AC breakdown strength is improved with the increase of concentration until a certain optimum concentration. When the concentration of nanoparticles is further increased, the AC breakdown voltage starts to decline. The authors concluded that this tendency of decline is due to agglomeration of nanoparticles which may result in reduction of breakdown voltage of nanofluid. Mansour et al. [57] also studied the effect of nanoparticles concentration on AC breakdown strength. The AC breakdown voltages were measured with different concentrations from $0.05 \mathrm{~g} / \mathrm{L}$ to $0.3 \mathrm{~g} / \mathrm{L}$. The authors found that AC breakdown voltage rises with the increase of concentration of nanoparticles. 


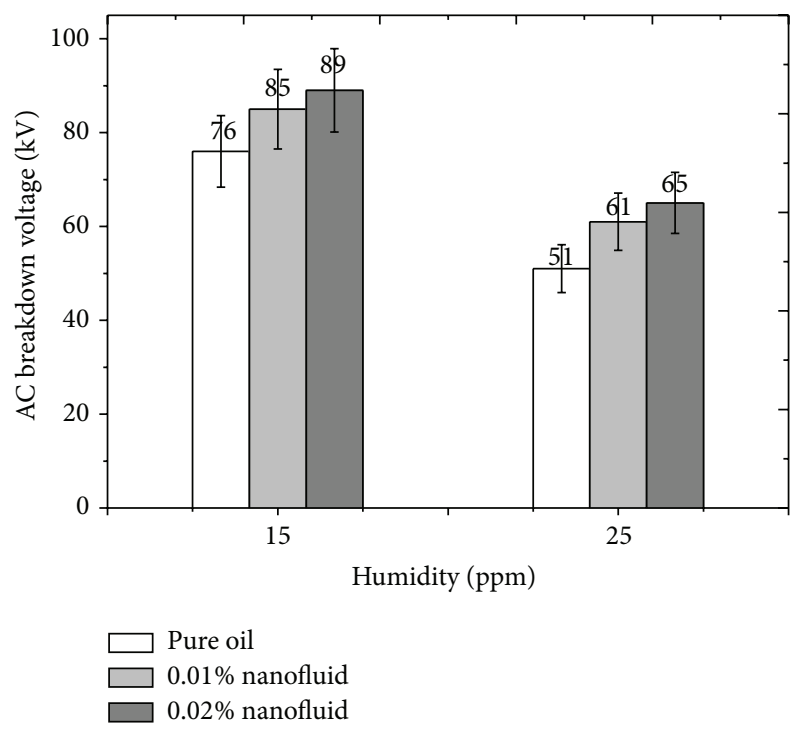

FIGURE 4: AC breakdown strength of mineral oil and silica nanofluids with $0.01 \%$ and $0.02 \%$ concentration as function of humidity [42].

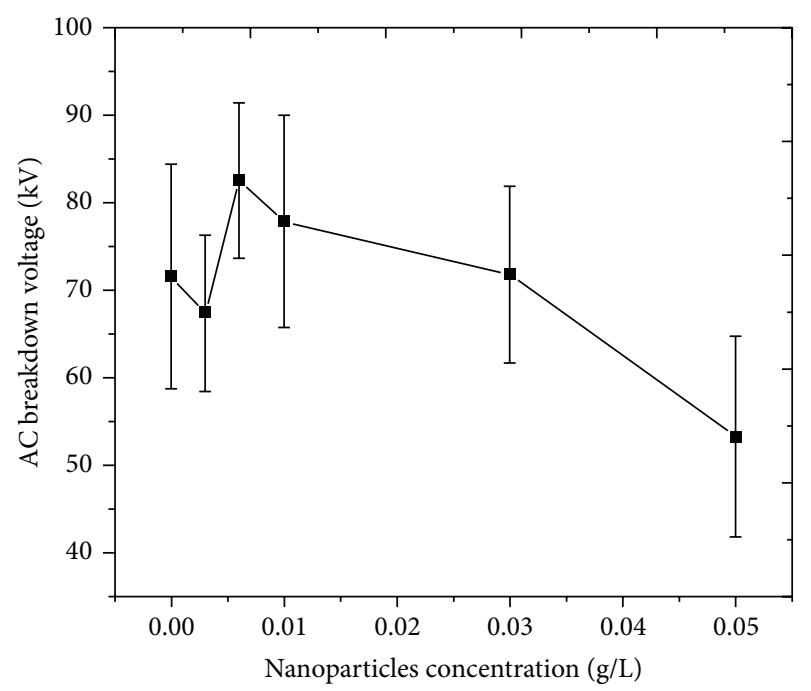

FIGURE 5: AC breakdown strength of pure oil and corresponding $\mathrm{TiO}_{2}$ nanofluids with different concentrations [43].

Rafiq et al. [32] conducted some experiments and measured AC breakdown strength of mineral oil and corresponding $\mathrm{Fe}_{3} \mathrm{O}_{4}$ nanofluids with different concentration of nanoparticles (5\% 80\% volume concentration) as shown in Figure 6 . The AC breakdown voltage showed maximum improvement at $40 \%$ concentration. At higher concentrations beyond $40 \%$, a decline in AC breakdown strength was observed and this decline was attributed to the agglomeration of nanoparticles. Du et al. [66] also studied the AC breakdown strength of mineral oil and corresponding $\mathrm{Fe}_{3} \mathrm{O}_{4}$ nanofluids with different concentration in a range from 0 to $300 \mathrm{ppm}$. The breakdown voltage increases with the increase in concentration until a maximum value of breakdown voltage and then starts to decrease. The authors concluded that agglomeration

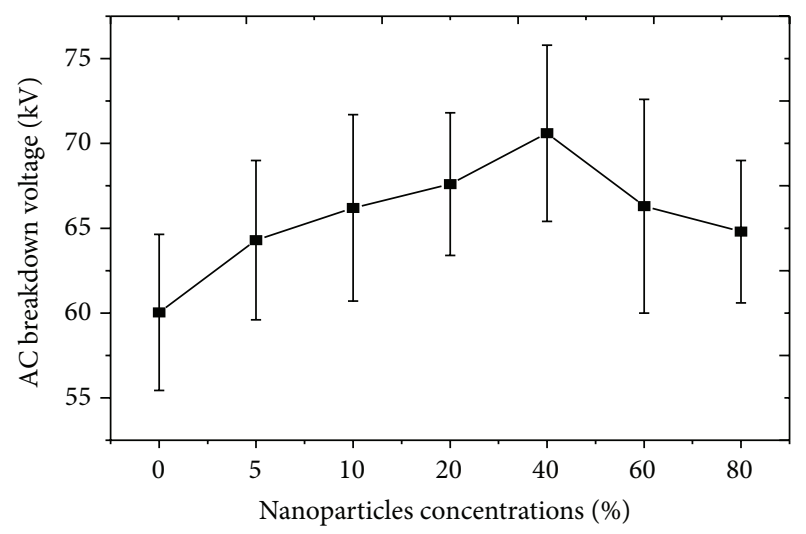

FIGURE 6: AC breakdown strength of pure oil and corresponding $\mathrm{Fe}_{3} \mathrm{O}_{4}$ nanofluids with different concentrations [32].

of nanoparticles is responsible for this decrease in breakdown voltage at high concentration.

Jin et al. [67] measured the AC breakdown voltage of pure mineral oil and corresponding fullerene nanofluids with concentration of $0.05 \%$ and $0.1 \%$ in accordance with IEC 60156 standard. The improvement in AC breakdown voltage was $19 \%$ for $0.05 \%$ fullerene concentration and $34 \%$ for $0.1 \%$ fullerene concentration as compared to oil. The authors explained this improvement of breakdown voltages of nanofluid by charge trap theory. The relaxation time constant is calculated to be between 75 and 80 ns which is less than the time scale involved for streamer propagation so the fullerene nanoparticles can act as charge traps in mineral oil. The higher the nanoparticle concentration, the more the charge traps, and hence the higher the breakdown voltage.

The above mentioned results lead to a conclusion that the particle aggregation has an adverse effect on the breakdown voltage of transformer oil but the reversible nanoparticle aggregation induced by electric field may have positive impact on breakdown voltage of transformer oil. This induced aggregation may be more effective in capturing the free electrons, reducing their mobility, leading to slower streamer formation and hence improving the breakdown voltages [68$71]$.

(iii) Surface Modification. Du et al. [44] studied the effect of different surface modification of $\mathrm{TiO}_{2}$ nanoparticles $(0.006 \mathrm{~g} /$ $\mathrm{mL}$ ) on the AC breakdown strength of transformer oil. Three different surface modifications were used to see the effect of surface modification on breakdown strength as shown in Figure 7. It was concluded that surface states of nanoparticles effectively influence the trapping and detrapping process of electrons and hence improve the breakdown strength of transformer oil.

(iv) Nanoparticle Type. Every nanoparticle has its own basic properties like electrical conductivity and permittivity which affects the relaxation time constant and hence the breakdown properties. A lot of different nanoparticles have been studied and analyzed by researchers to see their effect on AC breakdown strength of transformer oil. 


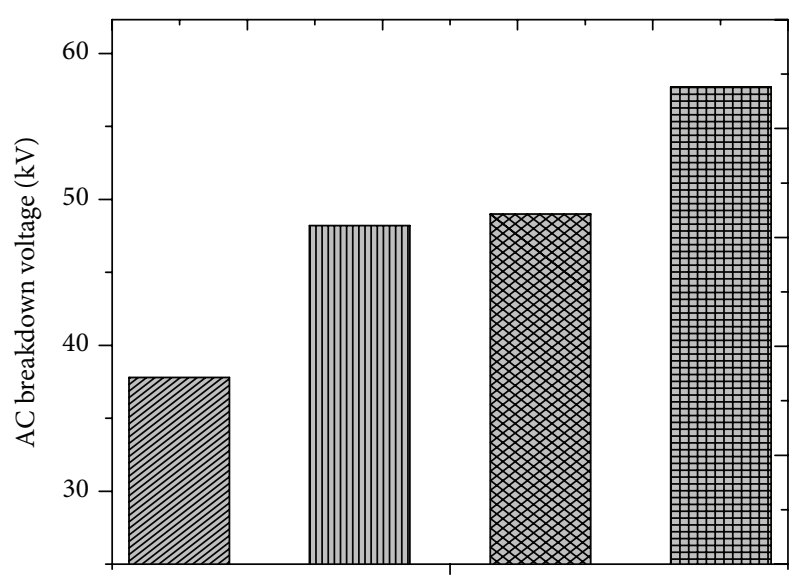

$$
\begin{aligned}
& \text { Pure oil } \\
& \text { س Untreated } \mathrm{TiO}_{2} \text { suspension } \\
& \text { س Silicon oil treated } \mathrm{TiO}_{2} \text { suspension } \\
& \text { Octadecanoic acid treated } \mathrm{TiO}_{2} \text { suspension }
\end{aligned}
$$

FIGURE 7: The influence of surface modification of $\mathrm{TiO}_{2}$ nanoparticles on AC breakdown strength of transformer oil [44].

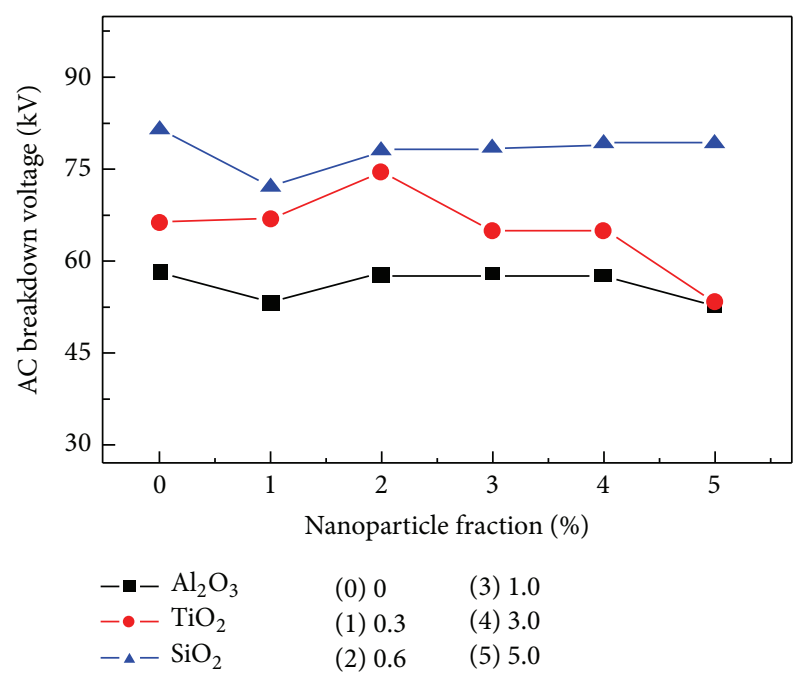

FIGURE 8: AC breakdown strength of nanofluids prepared with $\mathrm{Al}_{2} \mathrm{O}_{3}, \mathrm{TiO}_{2}$, and $\mathrm{Fe}_{3} \mathrm{O}_{4}$ nanoparticles with different nanoparticle loadings [45].

Lv et al. [45] have employed three types of nanoparticles with different dielectric properties to study their effect on the AC breakdown strength of transformer oil. No modification was used for all nanoparticles. The volume concentrations of nanoparticles in oil samples were in the range of 0 to $5 \% \mathrm{~g} / \mathrm{L}$. The comparison of AC breakdown strength of three types of nanoparticles is shown in Figure 8. The improvement of AC breakdown was explained by using the relaxation time constant of the nanoparticles.

Bakrutheen et al. [46] also studied the AC breakdown strength of nanofluids by using different types of nanoparticles. They prepared nanofluids by dispersing $\mathrm{TiO}_{2}, \mathrm{SiO}_{2}$, and $\mathrm{ZnO}$ separately into transformer oil with the particle volume

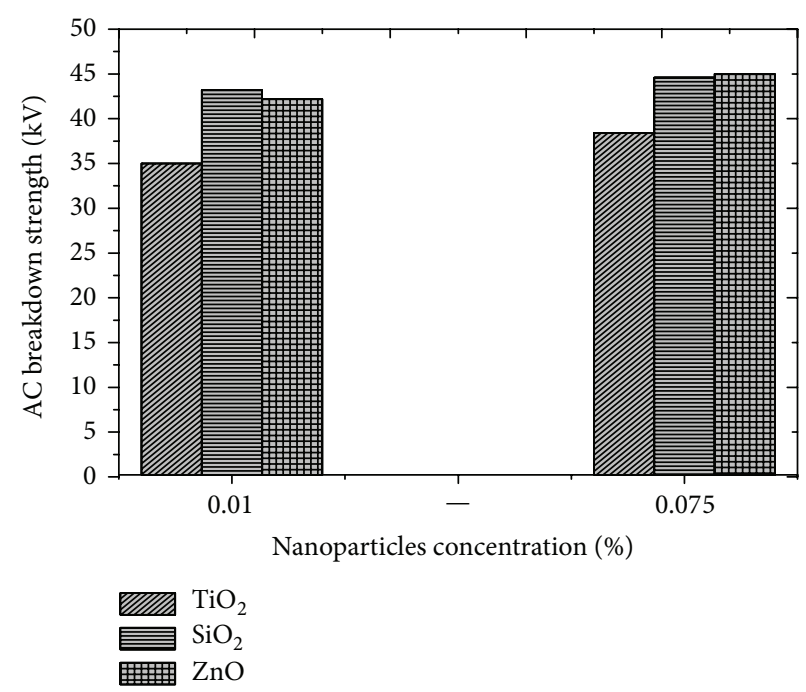

FIGURE 9: AC breakdown strength of nanofluids prepared with $\mathrm{SiO}_{2}$, $\mathrm{TiO}_{2}$, and $\mathrm{ZnO}$ nanoparticles with different nanoparticle concentrations [46].

concentrations of $0.01 \%$ and $0.075 \%$. They used three types of nanoparticles to prepare transformer oil-based nanofluids. They concluded that different types of nanoparticles significantly influence the breakdown strength of transformer oil as shown in Figure 9. The AC breakdown voltages measurement by different researchers is summarized in Table 2 .

(2) Impulse Breakdown Strength. The impulse breakdown voltage is simulating lightning strikes and usually uses a 1.2-microsecond rise for the wave to reach $90 \%$ amplitude and then drops back down to 50\% amplitude after 50 microseconds. The impulse breakdown voltages are measured normally by using IEC 60897 standard test and all the experiments are performed at room temperature. A lot of researchers measured the impulse breakdown strength of prepared nanofluids. In the following section the positive impulse breakdown voltage with respect to concentration and type of nanoparticles are presented. A lot of research has been carried out to measure the impulse breakdown strength of mineral oil-based and vegetable oil-based nanofluids $[22,23$, $27,31,37,61,72]$.

(a) Factors Affecting Impulse Breakdown Strength. The experimental studies have shown that impulse breakdown strength is affected by factors such as nanoparticle type and nanoparticle volume concentration. In the following section, experimental studies about impulse breakdown strength of transformer oil-based nanofluids are presented.

(i) Concentration of Nanoparticles. Du et al. [43] studied the lightening impulse breakdown strength of $\mathrm{TiO}_{2}$ nanofluids with different volume concentrations of nanoparticles as shown in Figure 10. The positive impulse breakdown increases with the increase of concentration until a certain optimal concentration after which breakdown voltages start to decline. The authors concluded that this decline of breakdown voltage is due to agglomeration of nanoparticles which 
TABLE 2: AC breakdown enhancement of transformer oil-based nanofluids reported in literature.

\begin{tabular}{|c|c|c|c|c|c|}
\hline Author/year & $\begin{array}{l}\text { Method of } \\
\text { preparation }\end{array}$ & Nanofluid & $\begin{array}{l}\text { Average particle } \\
\text { size }(\mathrm{nm})\end{array}$ & $\begin{array}{c}\text { Concentration } \\
\text { (vol\%) }\end{array}$ & Enhancement ratio \\
\hline Segal et al./1998 [22] & Two-step & $\mathrm{Fe}_{3} \mathrm{O}_{4} /$ mineral oil & 10 & - & $42.8 \%$ \\
\hline Sartoratto et al./2005 [27] & Two-step & $\mathrm{Fe}_{2} \mathrm{O}_{3} /$ mineral oil & 7.4 & 0.016 & $12.8 \%$ \\
\hline Du et al./2011 [28] & Two-step & $\mathrm{TiO}_{2} /$ mineral oil & 20 & 0.075 & $19 \%$ \\
\hline Liu et al./2012 [29] & Two-step & $\mathrm{SiO}_{2} /$ mineral oil & 15 & 0.0074 & $17 \%$ \\
\hline Li et al./2012 [30] & Two-step & $\mathrm{Fe}_{3} \mathrm{O}_{4} /$ vegetable oil & 30 & - & $19.8 \%$ \\
\hline Hanai et al./2013 [31] & Two-step & $\mathrm{ZnO} /$ mineral oil & 34 & 0.0005 & $8.3 \%$ \\
\hline Rafiq et al./2016 [32] & Two-step & $\mathrm{Fe}_{3} \mathrm{O}_{4} /$ mineral oil & $15-20$ & 0.04 & $16 \%$ \\
\hline
\end{tabular}

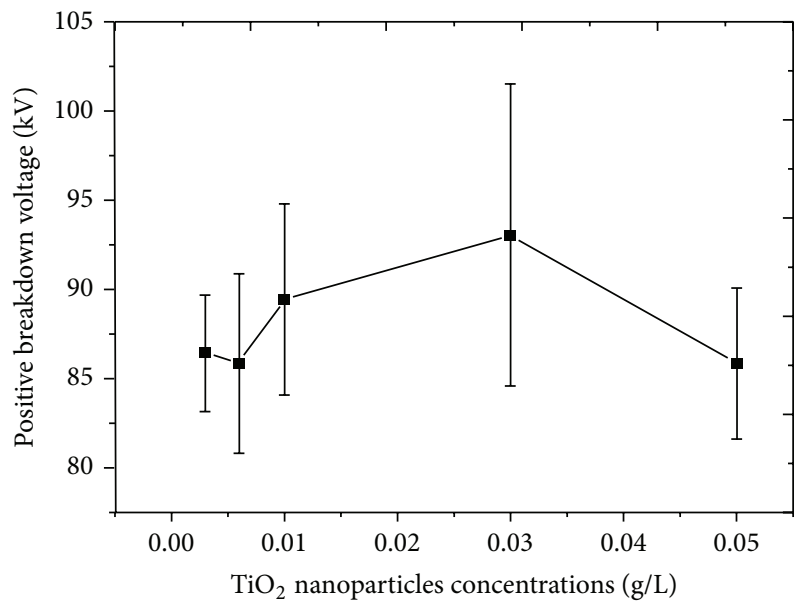

FIGURE 10: Positive impulse breakdown strength of nanofluids prepared with different $\mathrm{TiO}_{2}$ loadings [43].

may result in reduction of breakdown voltage of nanofluid at higher concentrations. Rafiq et al. [32] also did some experiments and measured positive impulse breakdown strength of mineral oil and corresponding $\mathrm{Fe}_{3} \mathrm{O}_{4}$ nanofluids with different volume concentration of nanoparticles $(5 \% \sim 80 \%)$ as shown in Figure 11. The positive impulse breakdown voltage showed maximum improvement at $40 \%$ concentration. At a higher concentration beyond $40 \%$, a decline in impulse breakdown strength was observed and this decline was attributed to the agglomeration of nanoparticles.

(ii) Nanoparticle Type. Every nanoparticle type is unique in its basic properties like conductivity and permittivity, which affects the relaxation time constant and hence the breakdown performance. Many different nanoparticles have been studied and analyzed by researchers to study their effect on impulse breakdown strength of transformer oil.

Sima et al. [33] measured impulse breakdown strength of three types of nanoparticles according to IEC608971987. The positive lightening impulse voltages of prepared nanofluids were significantly improved compared with pure oil. The time to impulse breakdown of nanofluids was also prolonged compared with pure oil as shown in Table 3. The authors concluded that every nanoparticle type affects the space charge distribution after capture of highly mobile electrons produced after ionization and hence influences the breakdown characteristics. The difference in the cause of

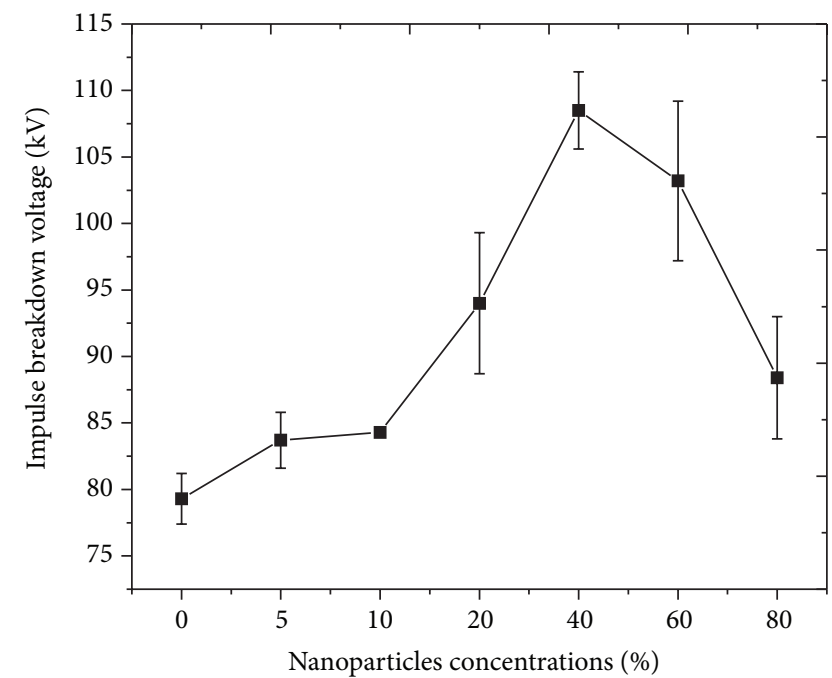

FIGURE 11: Positive impulse breakdown strength of nanofluids prepared with different $\mathrm{Fe}_{3} \mathrm{O}_{4}$ nanoparticle concentrations [32].

polarization between conductive and dielectric nanoparticles results in different breakdown properties among different types of nanofluids.

A lot of other researchers have also measured impulse breakdown strength of prepared nanofluids and pure oil. The summary of breakdown voltages with time to breakdown and streamer velocity is presented in Table 4.

(3) Partial Discharge Properties. Segal et al. [22] measured partial discharge inception voltage with a needle to sphere test geometry and found that colloid fluid has almost 30\% increases in PDIV as compared to the base fluid. Other researchers also [45] studied partial discharge characteristics (PD) of mineral oil by suspension of $\mathrm{TiO}_{2}$ nanoparticles. They found that PD inception voltage is enhanced and PD magnitude and impulse numbers are decreased (Table 5). The rise in $5 \%$ probability for nanofluid as compared to mineral oil indicates that the chance of partial discharge inception will be reduced by the access of nanoparticles. The authors suggested that these variations were caused by the high density of shallow electrons traps introduced by suspended $\mathrm{TiO}_{2}$ nanoparticles and hopping transport of electrons between these traps $[28,36]$. Herchl et al. [73] also analyzed the influence of conductive $\mathrm{Fe}_{3} \mathrm{O}_{4}$ nanoparticles on PD current in mineral oil by employing parallel plate 
TABLE 3: Breakdown results of pure oil and nanofluids [33].

\begin{tabular}{lcccccc}
\hline Material & \multicolumn{2}{c}{$\begin{array}{c}\text { Breakdown } \\
\text { voltage }(\mathrm{kV})\end{array}$} & \multicolumn{2}{c}{$\begin{array}{c}\text { Time to } \\
\text { breakdown }(\mu \mathrm{s})\end{array}$} & $\begin{array}{c}\text { Average streamer } \\
\text { velocity }(\mathrm{km} / \mathrm{s})\end{array}$ & $\begin{array}{c}\text { Enhancement of } \\
\text { breakdown voltage }(\%)\end{array}$ \\
\hline Pure oil & 51.84 & 0.48 & 4.44 & 0.33 & 1.126 & 0 \\
$\mathrm{Fe}_{3} \mathrm{O}_{4}$ nanofluid & 62.86 & 0.88 & 5.24 & 0.83 & 0.954 & 21.3 \\
$\mathrm{TiO}_{2}$ nanofluid & 65.72 & 1.10 & 5.40 & 0.65 & 0.926 & 26.8 \\
$\mathrm{Al}_{2} \mathrm{O}_{3}$ nanofluid & 66.24 & 1.14 & 6.12 & 0.68 & 0.817 & 27.8 \\
\hline
\end{tabular}

TABLE 4: Results for positive and negative impulse breakdown voltages and time to breakdown for mineral oil and corresponding nanofluids.

\begin{tabular}{|c|c|c|c|c|c|c|c|c|}
\hline \multirow{2}{*}{ Oils } & \multirow{2}{*}{ Gap distance $(\mathrm{mm})(+/-)$} & \multicolumn{2}{|c|}{ Breakdown voltage $(\mathrm{kV})$} & \multicolumn{2}{|c|}{ Time to breakdown $(\mu \mathrm{s})$} & \multicolumn{2}{|c|}{ Streamer velocity $(\mathrm{km} / \mathrm{s})$} & \multirow{2}{*}{ Remarks } \\
\hline & & Positive & Negative & Positive & Negative & Positive & Negative & \\
\hline $\mathrm{U}-60^{\mathrm{a}}$ & $25.4 / 25.4$ & 86 & 170 & 12 & 27 & 2.12 & 0.94 & \multirow{6}{*}[5]{} \\
\hline $\mathrm{U}-60-\mathrm{Fe}_{3} \mathrm{O}_{4}$ nanofluid & $25.4 / 25.4$ & 157 & 154 & 26 & 15 & 0.98 & 1.70 & \\
\hline Nytro $^{\mathrm{b}}$ & $25.4 / 25.4$ & 88 & 177 & 16 & 23 & 1.58 & 1.10 & \\
\hline Nytro- $\mathrm{Fe}_{3} \mathrm{O}_{4}$ nanofluid & $25.4 / 25.4$ & 156 & 173 & 25 & 17 & 1.016 & 1.49 & \\
\hline $\mathrm{U}-60^{\mathrm{a}}$ & $55 / 55$ & 225 & 340 & 25 & 28 & 2.2 & 1.96 & \\
\hline $\mathrm{U}-60-\mathrm{Fe}_{3} \mathrm{O}_{4}$ nanofluid & $55 / 55$ & 390 & 321 & 46 & 32 & 1.19 & 1.71 & \\
\hline Mineral oil & $25 / 25$ & 77.6 & - & 15.2 & - & 1.64 & - & \multirow{2}{*}[34]{} \\
\hline $\mathrm{TiO}_{2}$ nanofluid & 25 & 95.9 & - & 23.3 & - & 1.07 & - & \\
\hline Mineral oil & $25 / 25$ & 86 & 170 & 12 & 27 & 2.12 & 0.94 & \multirow{3}{*}[35]{} \\
\hline $\mathrm{Fe}_{3} \mathrm{O}_{4}$ nanofluid & - & 157 & 154 & 26 & 15 & 0.98 & 1.69 & \\
\hline $\mathrm{SiO}_{2}$ nanofluid & - & 156 & 163 & 17 & 26 & 1.44 & 2.87 & \\
\hline Mineral oil & $25 / 15$ & 79.38 & 124.75 & 12.87 & 14.26 & 1.94 & 1.05 & \multirow[b]{2}{*}[29]{} \\
\hline $\mathrm{Fe}_{3} \mathrm{O}_{4}$ nanofluid & $25 / 15$ & 108.5 & 106.3 & 25.33 & 11.03 & 0.98 & 1.36 & \\
\hline
\end{tabular}

${ }^{\mathrm{a}}$ Univolt 60 Exxon mineral oil.

${ }^{\mathrm{b}}$ Nytro 10x mineral oil. The standard deviation was $5 \%$ for the breakdown voltages and $20 \%$ for the breakdown times.

TABLE 5: Partial discharge voltages (PDIV), impulse numbers, and partial discharge magnitudes measurement at 1.0 and 2.0 PDIV of mineral oil and nanofluid [19].

\begin{tabular}{lcccccccc}
\hline & & & & & \multicolumn{2}{c}{ Measurements at 1.0 PDIV } & \multicolumn{2}{c}{ Measurements at 2.0 PDIV } \\
Materials & PDIV $(\mathrm{kV})$ & SD & $\begin{array}{c}5 \% \\
\text { probability } \\
\text { PDIV }(\mathrm{kV})\end{array}$ & $\begin{array}{c}63.2 \% \\
\text { probability } \\
\text { PDIV }(\mathrm{kV})\end{array}$ & Pulse number & $\begin{array}{c}\text { Mean } \\
\text { discharge } \\
\text { magnitude } \\
\text { (pC) }\end{array}$ & $\begin{array}{c}\text { Pulse number } \\
\text { discharge } \\
\text { magnitude } \\
(\mathrm{pC})\end{array}$ \\
\hline Mineral oil & 30.6 & 2.7 & 25 & 31.7 & 9 & 435 & 245 \\
Nanofluid & 33.1 & 1.8 & 29.5 & 33.8 & 6 & 245 & 168 \\
\hline
\end{tabular}

electrodes at different gap distance. They concluded that the magnitudes of PD current in the nanofluids first reduced with increase of nanoparticle concentrations and then increased at all studied gap distances. Jin [74] also measured the inception voltage of silica and fullerene nanofluids with $0.01 \%$ nanoparticle concentration under DC positive voltages and the results are presented in Table 6.

(4) Dielectric Properties. Du et al. [36] and Ramu et al. [37] measured basic electric parameters of both mineral oil and corresponding nanofluids (Table 7). The results of resistivity of nanofluids showed a downshift with respect to typical value of the transformer oil but still they meet the quality of transformer oil in service. However, value of the relative permittivity is higher than mineral oil which is favorable in producing a uniform electric field in oil-paper insulation system.

Sartoratto et al. [27] measured the dielectric properties of transformer oil-based magnetic nanofluids with different concentrations as shown in Table 8 . Dielectric properties were measured for samples with $0.80 \%-0.0040 \%$ maghemite volume fractions. There was huge variation in the relative permittivity from 8.8 to 2.1 . The resistivity was noted in the range of $0.7-2.5 \times 10^{10} \Omega \mathrm{m}$. Mergos et al. [47] also measured the dielectric properties of paraffin oil suspended with $\mathrm{TiO}_{2}$, $\mathrm{Al}_{2} \mathrm{O}_{3}, \mathrm{Fe}_{2} \mathrm{O}_{3}, \mathrm{CuO}$, and $\mathrm{Cu}_{2} \mathrm{O}$ nanoparticles. They concluded that dielectric properties of nanofluids mainly depend on grain size of nanoparticle and chemical composition of 
TABLE 6: Inception voltage and partial discharge magnitude measurement of mineral oil and nanofluids under positive DC voltage.

\begin{tabular}{lcccc}
\hline Materials & PDIV $(\mathrm{kV})$ & SD & $\begin{array}{c}\text { 50\% probability discharge } \\
\text { magnitude }(\mathrm{pC})\end{array}$ & $\begin{array}{c}\text { 63.2\% probability discharge } \\
\text { magnitude }(\mathrm{pC})\end{array}$ \\
\hline Mineral oil & 22 & 4 & $49( \pm 4)$ & $54( \pm 4)$ \\
$0.01 \%$ silica nanofluid & 27 & 4 & $18( \pm 2)$ & $21( \pm 3)$ \\
$0.01 \%$ fullerene nanofluid & 25 & 3 & $33( \pm 3)$ & $36( \pm 3)$ \\
\hline
\end{tabular}

TABLE 7: Relative permittivity and resistivity of mineral oil and nanofluids [36, 37].

\begin{tabular}{|c|c|c|c|c|}
\hline Samples & Resistivity $(\Omega \cdot \mathrm{m})$ & Permittivity & Loss factor & Remarks \\
\hline Mineral oil & $6.25 \times 10^{13}$ & 2.2 & 0.0047 & \multirow{3}{*}{ [37] } \\
\hline $\mathrm{Fe}_{3} \mathrm{O}_{4} /$ mineral oil & $3.63 \times 10^{7}$ & 36.5 & 2.87 & \\
\hline $\mathrm{SiO}_{2} /$ mineral oil & $7.14 \times 10^{14}$ & 2.2 & 0.0016 & \\
\hline Mineral oil & $1.82 \times 10^{12}$ & 2.26 & - & \multirow[b]{2}{*}[36]{} \\
\hline $\mathrm{TiO}_{2} /$ mineral oil & $8.30 \times 10^{10}$ & 3.92 & - & \\
\hline
\end{tabular}

TABLE 8: Electrical properties of the magnetic fluids compared to those of mineral oil $[27,38]$.

\begin{tabular}{lccccc}
\hline \multirow{2}{*}{ Volume concentration \% } & \multicolumn{2}{c}{ Resistivity $\left(\times 10^{10} \Omega\right)$} & Loss factor & Relative permittivity & Breakdown strength $(\mathrm{kV})$ \\
\hline 0 & RHO- & RHO+ & & 2.1 & 70 \\
0.800 & 36.0 & 19.7 & 0.00366 & 8.8 & - \\
0.016 & 0.0021 & 0.0028 & 2.389 & 2.1 & 79 \\
0.008 & 0.73 & 0.63 & 0.399 & 2.1 & 72 \\
0.004 & 1.75 & 0.95 & 0.1868 & 2.1 & 70 \\
\hline
\end{tabular}

nanoparticles. Surface polarization of nanoparticles induced by water absorbed also affects the dielectric characteristics of nanofluid.

(5) Thermal Aging. The effect of suspension of nanoparticles into transformer oil on aging was studied by Segal et al. [22]. The $\mathrm{Fe}_{3} \mathrm{O}_{4}$ nanofluids and base oil were thermally aged at $185^{\circ} \mathrm{C}$. The results of $\mathrm{AC}$ and impulse breakdown indicated that the addition of $\mathrm{Fe}_{3} \mathrm{O}_{4}$ nanoparticles enhanced the resistance of oil to thermal aging (Figure 12). The aged nanofluids sustained their improved breakdown strength even after 12 weeks after being thermally aged at $185^{\circ} \mathrm{C}$. Lv et al. [75] also studied the influence of $\mathrm{TiO}_{2}$ nanoparticles on the insulating properties of aged mineral oil. The samples were aged at $130^{\circ} \mathrm{C}$ for 36 days. The results manifested that the mean $\mathrm{AC}$ and positive impulse breakdown strength of $\mathrm{TiO}_{2}$ nanofluids were improved by factors of 2.21 and 1.33 , respectively, as compared to aged base oil. The authors concluded that $\mathrm{TiO}_{2}$ nanoparticles significantly decrease the distortion in the modified aged oil by the introduction of shallow traps in which electrons are trapped and detrapped continuously and hence improve the dielectric strength of the aged nanofluid.

$\mathrm{Hu}$ et al. [76] investigated the effect of semiconductive nanoparticles $\mathrm{TiO}_{2}(d<20 \mathrm{~nm})$ on the insulating properties of aged transformer oil. The mineral oil and nanofluids were aged at $130^{\circ} \mathrm{C}$ for 36 days. The nanofluids always presented better insulating characteristics as compared with pure oil during all 36 days of thermal aging process. After 36

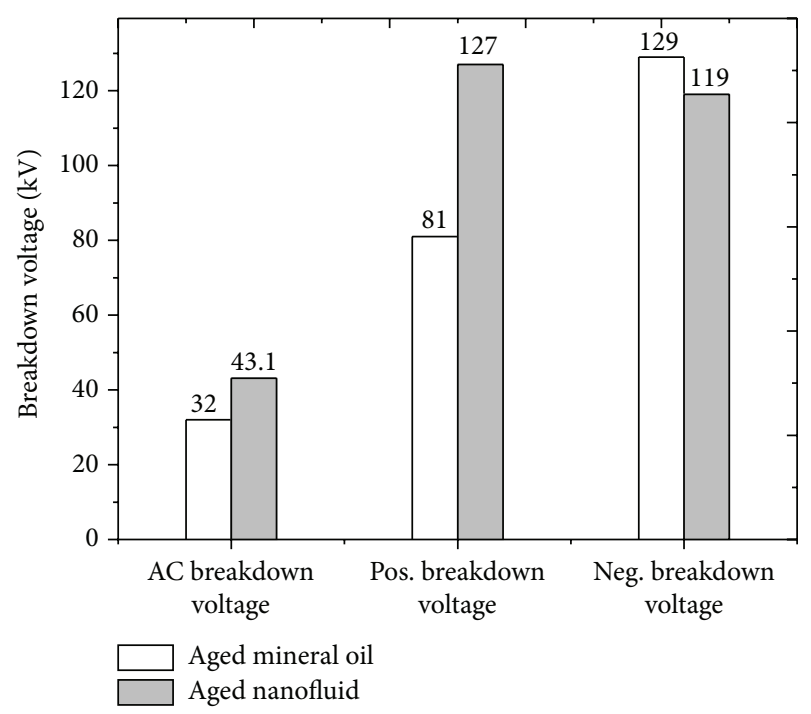

FIGURE 12: AC and impulse breakdown voltages for mineral oil and the nanofluid containing $\mathrm{Fe}_{3} \mathrm{O}_{4}$ nanoparticles, after aging for 12 weeks at $185^{\circ} \mathrm{C}$ [47].

days of aging, AC breakdown voltage, PDIV, and lightening impulse voltage were $1.4,1.1$, and 1.03 times those of pure oil, respectively. The results manifested transformer oil-based nanofluid holds not only better insulating properties but also appreciable aging resistance. 
Lv et al. [77] investigated AC breakdown voltage, impulse breakdown voltage, and PDIV of aged pure oil and corresponding $\mathrm{TiO}_{2}$ (with avg. particle size $d<10 \mathrm{~nm}$ ) nanofluids. Accelerated thermal aging was carried out at $130^{\circ} \mathrm{C}$ for 6 days. The range of nanoparticles concentration was from 0 to $0.125 \%$. The low as well as high moisture content of prepared samples was controlled at almost 5 ppm and $15 \mathrm{ppm}$. The results of AC, impulse breakdown, and PDIV are shown in Figures 13, 14, and 15. The authors concluded that AC breakdown voltage of aged nanofluids is enhanced at all concentrations. The maximum AC breakdown voltage improvement was 7.7\% (at $5 \mathrm{ppm}$ ) and $17.5 \%$ (at $15 \mathrm{ppm}$ ). The impulse breakdown voltage was also improved at all concentrations. An enhancement of $49.4 \%$ of impulse breakdown voltages was observed and time to breakdown was also significantly prolonged. A maximum improvement of $27.9 \%$ in PDIV was seen at moisture content of $15 \mathrm{ppm}$. These results demonstrated that $\mathrm{TiO}_{2}$ nanoparticles not only dramatically improve the antiaging characteristics of mineral oil but also greatly enhance its moisture resistance. Transformer oilbased nanofluids with $\mathrm{TiO}_{2}$ semiconductive nanoparticles manifested higher breakdown voltages than that of pure oils at higher humidity. It reveals that the nanofluids have more uniform internal electric fields and higher charge decay rate as compared to pure oils under high relative humidity. It is observed by test results of electrophoresis and thermally stimulated current (TSC) that the nanoparticles absorb water molecules at nanoparticle and oil interface, giving rise to higher of shallow trap density and resulting in better charge transport in nanofluids.

(6) Dielectric Modification Mechanisms. The mechanism through which nanoparticles affect the breakdown properties of oil is still not fully elaborated. The classic theory of dielectric breakdown of liquids is unable to describe the insulating characteristics enhancement of transformer oil-based nanofluids [38]. Therefore other mechanisms of modification of nanoparticles have been proposed.

In 2008, George Hwang et al. [24] presented a model to describe the enhancement in the insulating strength of oil with homogenous $\mathrm{Fe}_{3} \mathrm{O}_{4}$ suspension. He suggested that the dispersed conductive nanoparticles capture the electrons and reduce their mobility and energy transfer. This was the major reason behind the dielectric performance improvement and reduction in positive streamer velocity in the prepared nanofluids. The high mobility electrons produced as a result of electric field ionization are trapped by suspended $\mathrm{Fe}_{3} \mathrm{O}_{4}$ nanoparticles, which then converted to slow negative charge carriers. The theory of charge relaxation time was brought in to elaborate the principal electrodynamic process. The relaxation time constant is given by

$$
\tau_{r}=\frac{2 \varepsilon_{1}+\varepsilon_{2}}{2 \sigma_{1}+\sigma_{2}},
$$

where $\sigma_{1}$ and $\sigma_{2}$ are conductivities of transformer oil and nanoparticles, respectively; $\varepsilon_{1}$ and $\varepsilon_{2}$ are the permittivities of transformer oil and nanoparticles, respectively. A small value of relaxation time constant means fast absorption of electrons on the surface of the nanoparticles. The relaxation time constant for conductive nanoparticles $\mathrm{Fe}_{3} \mathrm{O}_{4}$ is less than the propagation time constant of the streamer. Therefore, the surface of the nanoparticles can capture free electrons rapidly, thus modifying the potential distribution around the nanoparticles [24].

The relaxation time constant for conductive nanoparticles $\mathrm{Fe}_{3} \mathrm{O}_{4}$ is $7.47 \times 10^{-14} \mathrm{~s}$, which is short in comparison with streamer development time scale in mineral oil. Therefore, as previously mentioned, the $\mathrm{Fe}_{3} \mathrm{O}_{4}$ nanoparticles get briskly polarized after the electric field application, trapping high mobility electrons and thereby being converted to slow negatively charged carriers (Figure 16). The growth of net space charge zone at streamer tip is impeded because of these slow moving charge carriers and thus restrains the propagation of streamer in the oil and results in a higher breakdown performance [38].

Nevertheless, this model is unable to describe the decline in breakdown voltages of transformer oil-based SiC nanofluids as compared to host oil even if the relaxation time constant of mineral oil-based $\mathrm{SiC}$ nanofluid is $\left(1.1 \times 10^{-12} \mathrm{~s}\right)$ which is far less than the timescale of streamer development in mineral oil [52]. It also cannot explain the enhanced breakdown strength of oil modified by nanoparticles with longer relaxation time constant than the timescale of streamer development in mineral oil $[38,44,62]$.

Du et al. [28] presented a model to explain the improvement of dielectric performance of transformer oil suspended with semiconductive nanoparticles. They suggested that suspended $\mathrm{TiO}_{2}$ introduce traps that trap the high mobility electrons. This trapping and detrapping process slows down the electrons responsible for streamer development and hence improves dielectric strength of transformer oil. The thermally stimulated current (TSC) plot for nanofluid and transformer oil is shown in Figure 17. As is clear from this plot, the height of TSC peak for $\mathrm{TiO}_{2}$ nanofluids is almost 2.5 times the base oil peak, which indicates that there is high density of electron traps in nanofluids. This high density electron trap reduces the mobility and average energy of electrons moving through the oil, and so the chances of further generation of electrons through impact ionization would also be decreased. Therefore, the distortion of electric field in the transformer oil by electronic charge will be diminished and dielectric strength improved [38].

2.2.2. Physical and Thermal Properties. Physical and thermal properties of transformer oil are also equally important as electrical properties because the transformer oil is required to perform both of its functions of insulation and cooling efficiently. The following section will give an overview of physical and thermal properties of transformer oil.

(1) Thermal Conductivity. Thermal conductivity is a property of a material describing its ability to conduct heat. Transformer liquids are expected to act as an electrically insulating and heat transfer medium. Thermal conductivity is a vital parameter in improving the heat transfer of a base fluid. It is therefore desirable for the fluid to possess high thermal conductivity. The thermal conductivity and more generally heat transfer characteristics of the materials are 


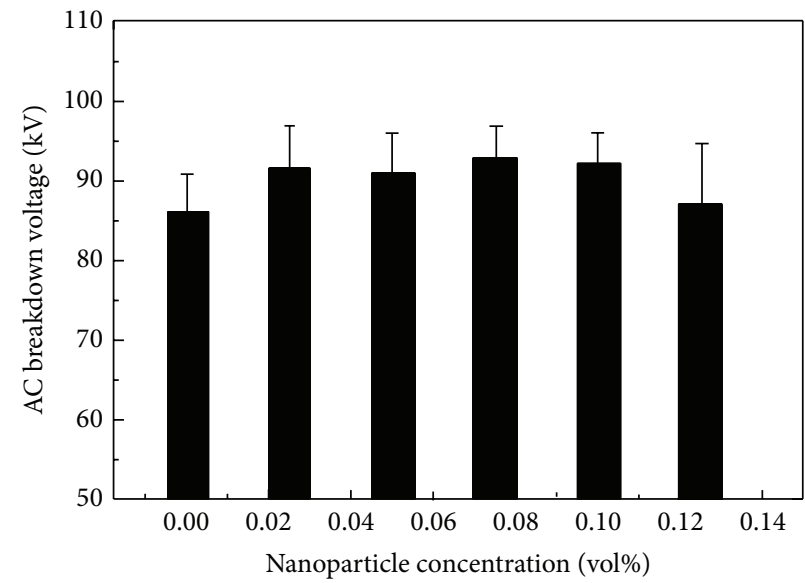

(a)

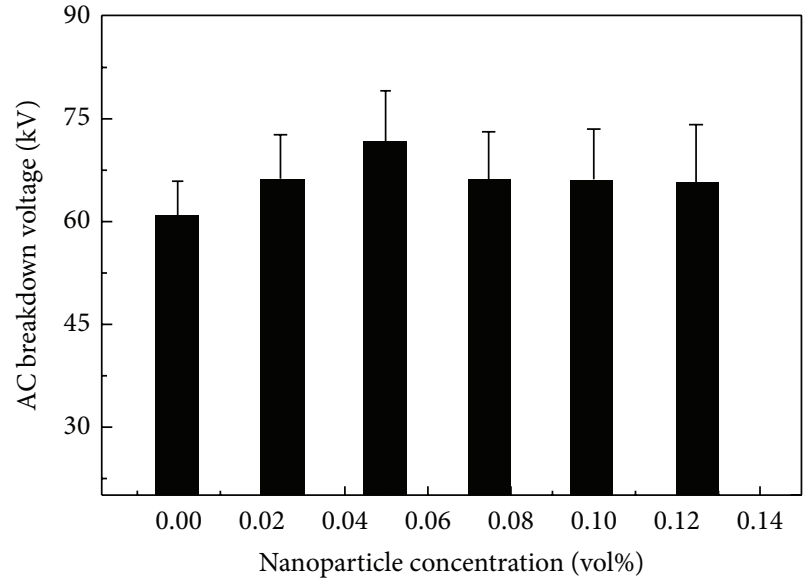

(b)

FIGURE 13: AC breakdown voltages of aged oil samples with 5 ppm (a) and 15 ppm (b) moisture content.

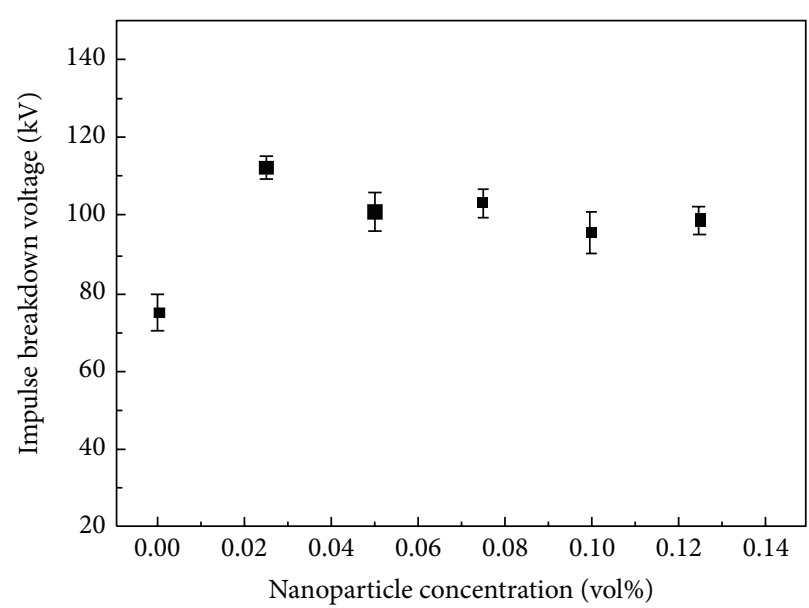

(a)

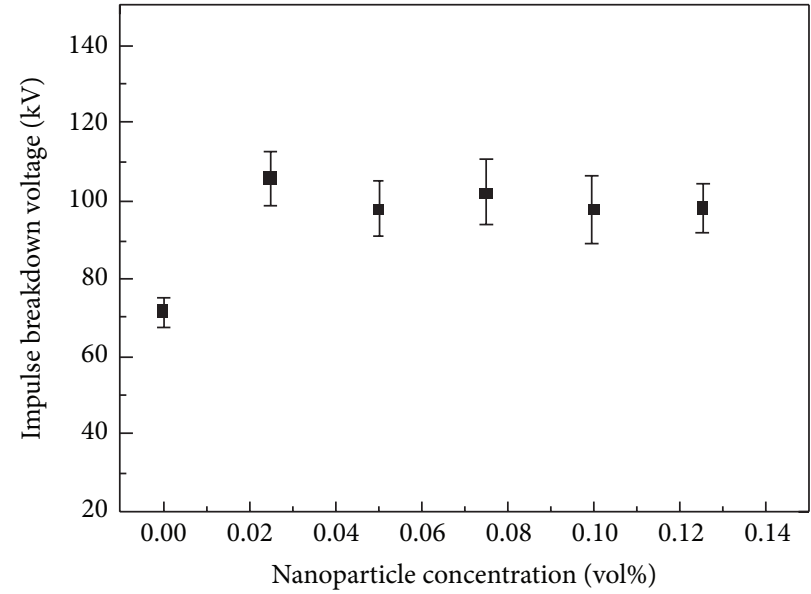

(b)

FIGURE 14: Positive impulse breakdown voltages of aged oil samples with $5 \mathrm{ppm}$ (a) and $15 \mathrm{ppm}$ (b) moisture content.

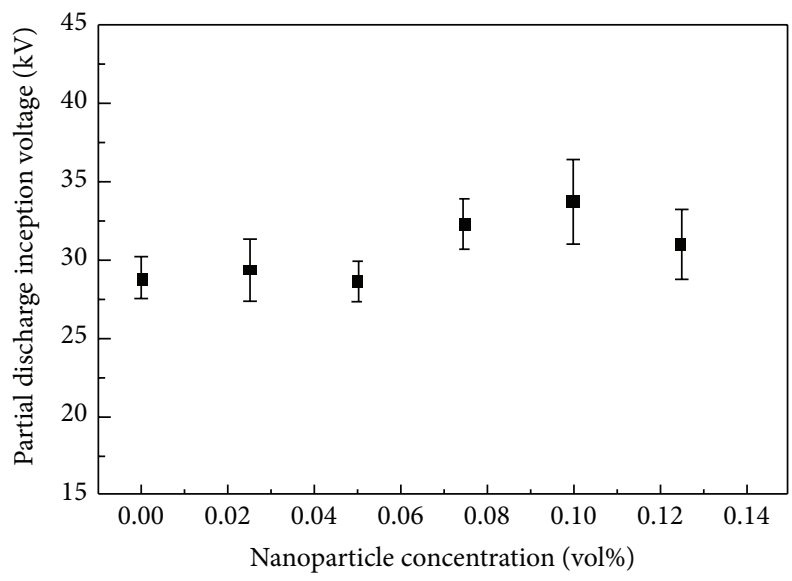

(a)

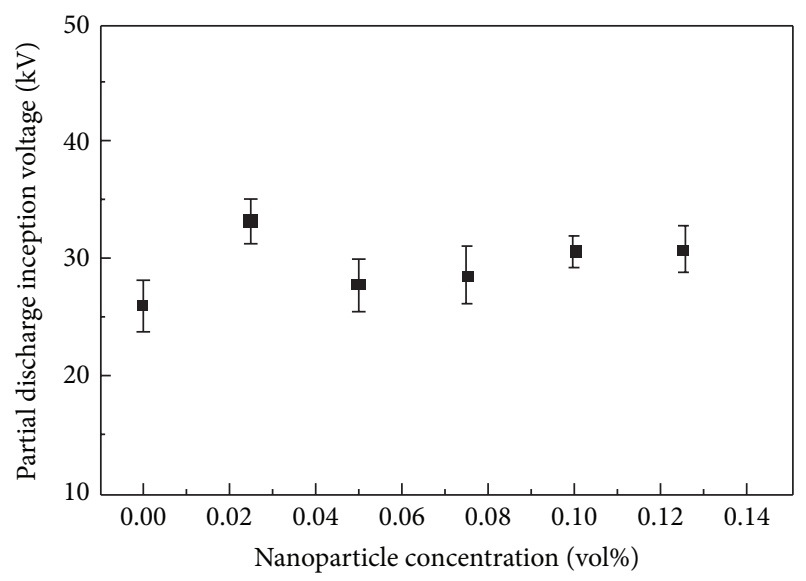

(b)

FIGURE 15: PDIV of aged oil samples with low (a) and high (b) moisture content. 


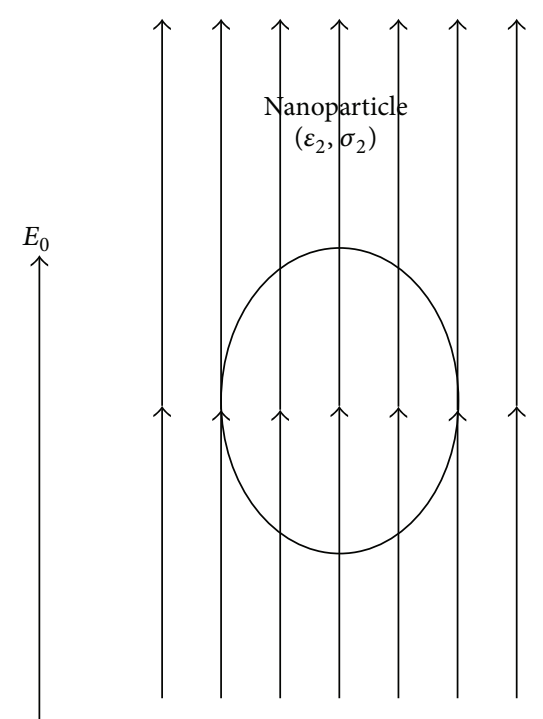

(a)

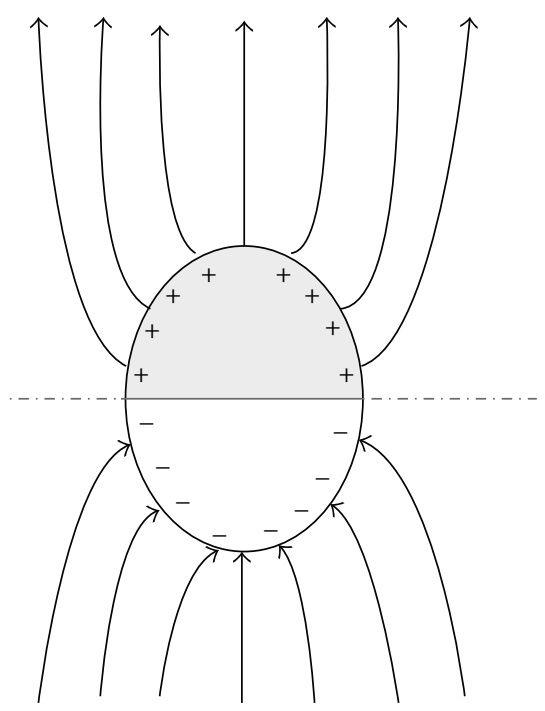

(b)

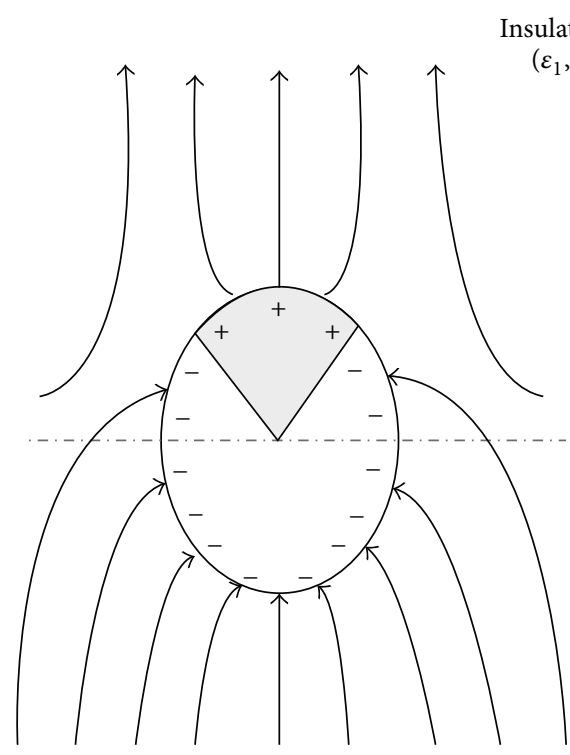

(c) ulating oil $\left(\varepsilon_{1}, \sigma_{1}\right)$

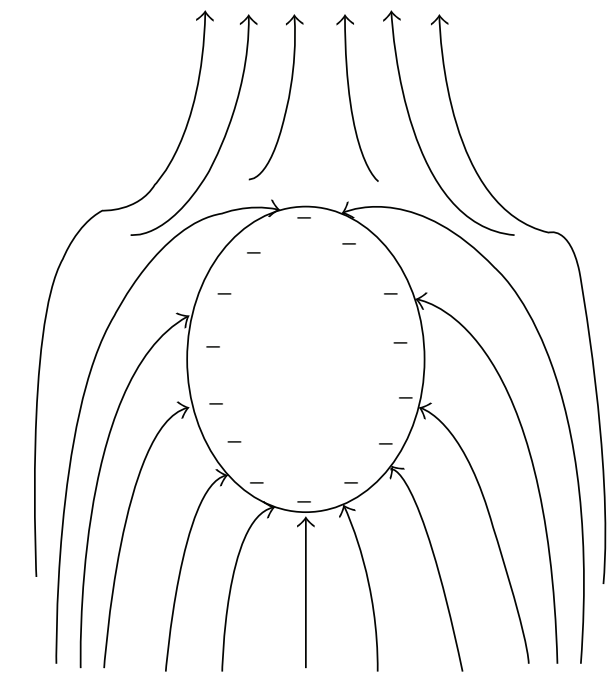

(d)

FIGURE 16: Surface charge distribution and polarization of conductive $\mathrm{Fe}_{3} \mathrm{O}_{4}$ nanoparticles in mineral oil [24].

considered decisive in the selection of transformer liquid. The suspension of different types of nanoparticles into transformer oil affects its thermal conductivity and suspended nanoparticles are expected to enhance their thermal conductivity and heat transfer performance. Many researchers have reported research studies on the thermal conductivity of nanofluids. Transformer oil is required to have a high thermal conductivity and low viscosity to be a good heat transfer fluid. As the thermal conductivity of mineral oil is low, there are high chances of thermally driven failures from instantaneous overloading. Therefore, it is required to look for ways to enhance the thermal conductivity of transformer oil to achieve extension in lifetime of transformer and improvement in cooling and enhance loading capacity. Ideal transformer oil should possess high thermal conductivity to dissipate heat away and low viscosity to facilitate flow of oil continuously and excellent insulating characteristics. Obviously, the right choice is to add nanoparticles in oil to take heat away by enhancing thermal conductivity of oil. The thermal conductivity of copper oil-based nanofluids increases by increasing mass fraction of nanoparticle for various fluid-based nanofluids [78]. The thermal conductivity found was enhanced by the suspension of silica nanoparticles [79] and alumina nanoparticles [80].

(a) Factors Affecting Thermal Conductivity. The experimental studies have indicated that thermal conductivity of nanofluids depends on many factors such as nanoparticle type, nanoparticle volume concentration, size of nanoparticle, shape of nanoparticle, base liquid, and temperature. The type 


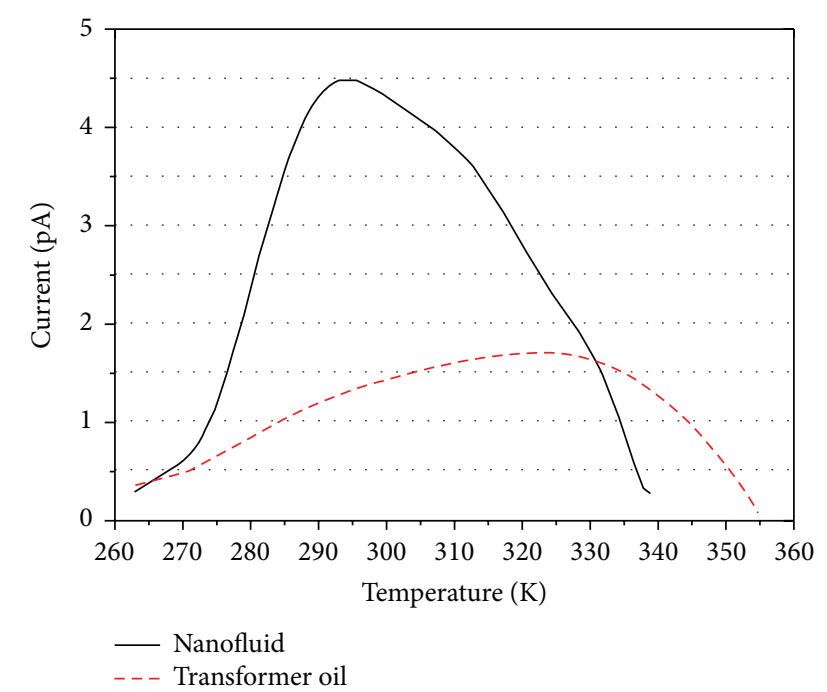

FIGURE 17: Thermally stimulated current (TSC) for mineral oil and mineral oil-based $\mathrm{TiO}_{2}$ nanofluid [28].

and amount of additive were also found to be effective in the improvement of thermal conductivity. In the following section, experimental studies about thermal conductivity of transformer oil-based nanofluids are presented.

(i) Particle Volume/Mass Fraction. There are studies in the literature about the influence of nanoparticle concentration in oil on the thermal conductivity of oil. Some research work manifested a linear behavior of thermal conductivity with nanoparticle concentration; however a few show a nonlinear behavior.

Li et al. [78] investigated thermal conductivity of $\mathrm{Cu}$ nanoparticles and kerosene as base fluid in nanofluid. The range of mass fraction selected was 0 to $0.0100 \%$. The thermal conductivity of $\mathrm{Cu}$ nanofluid increases with enhancement of mass fraction of nanoparticles. The relationship between the thermal conductivity enhancement and the mass fraction was nonlinear.

Singh and Kundan [80] investigated thermal conductivity of $\mathrm{Al}_{2} \mathrm{O}_{3}$ nanoparticles and mineral oil (Transol) as base fluid in nanofluid. $\mathrm{Al}_{2} \mathrm{O}_{3}$ nanoparticles with diameter $20 \mathrm{~nm}$ were dispersed into mineral oil $(0.1,0.3,0.5$, and 1.0 vol. \% volume concentration) at temperature $20^{\circ} \mathrm{C} \sim 50^{\circ} \mathrm{C}$. The maximum enhancement in thermal conductivity was $4 \%$ and it was observed in volume concentration range 0.1 to $0.3 \%$.

Fontes et al. [81] measured thermal conductivity of samples of diamond nanoparticles and multiwalled carbon nanotubes (MWCNT) dispersed in transformer oil. The samples were developed for nanoparticles volumetric concentrations of $0.005 \%, 0.01 \%$, and $0.05 \%$ through two-step method. The results indicated that the thermal conductivity of nanofluids increases by increasing the nanoparticles concentration. The maximum enhancement was of $27 \%$ and $23 \%$ for MWCNT and diamond nanoparticles, respectively. This improvement was higher than the predictions provided by effective medium theory using equation proposed by Maxwell [82].
Zeng et al. [83] studied the heat transfer of oil-based nanofluids consisting of lipophilic nanoparticles with varying mass fraction from $0.25 \%$ to $1.0 \%$. Thermal conductivity was measured at a temperature range from 40 to $200^{\circ} \mathrm{C}$. It was noted that the nanofluids have higher thermal conductivity and thermal conductivity increased not only with increase in mass fraction of nanoparticles, but also with rise in temperature in the range $40-180^{\circ} \mathrm{C}$. The results manifested $38.7 \%$ improvement of thermal conductivity of $\mathrm{MoS}_{2}$ nanofluid at $180^{\circ} \mathrm{C}$ with $1.0 \%$ mass fraction.

Jin [74] measured thermal conductivity of silica and fullerene nanoparticles and mineral oil as base fluid in nanofluid. $\mathrm{SiO}_{2} /$ fullerene nanoparticles of diameter $10-20 / 1 \mathrm{~nm}$ were dispersed in mineral oil ( 0.01 and $0.1 \%$ volume concentration) at temperature $10^{\circ} \mathrm{C} \sim 80^{\circ} \mathrm{C}$. A negligible effect was noticed on thermal conductivity with these concentrations of nanoparticles. A possible explanation is that the nanoparticle concentration is too small to have any effect on the oil. The lowest mass fraction which has positive effect on thermal conductivity of oil is $5 \%[74,78,83]$. The summary of the results obtained by some other authors is presented in Table 9.

(ii) Nanoparticle Type. The nanoparticle type is also an important factor for investigating the thermal conductivity of nanofluid. Difference in thermal conductivity of particle materials is one of major parameters for various kinds of properties shown by different nanofluids with different types of nanoparticles. Nevertheless, research indicates that particle type may influence the thermal conductivity of nanofluids in other ways. Chen et al. [84] investigated thermal conductivity of oil-based nanofluids suspended with multiwalled carbon nanotubes (MWCNT). The measurement was conducted at room temperature and results indicated an enhancement of $160 \%$. The author concluded that this enormous improvement is because of traits of nanoparticles.

(iii) Base Fluid. The viscosity of base fluids affects the Brownian motion of nanoparticles and in turn influences the thermal conductivity of nanofluid [85]. Furthermore, Gobin et al. [86] studied the effect of electric double layer formed around nanoparticle on the thermal conductivity of nanofluid and concluded that electric double layer and thermal conductivity depend on base fluid. Therefore the effect of vegetable oil on thermal conductivity as base fluid will be different than the effect of mineral oil as base fluid. It is hard to determine effect quantitatively; therefore more extensive research work is required that will indicate the effect of base fluid on thermal conductivity of nanofluid.

(iv) Temperature. Generally, thermal conductivity of nanofluids is more temperature dependant as compared to base fluid. Therefore, thermal conductivity improvement of nanofluids is also temperature sensitive.

Patel et al. [87] studied thermal conductivity of nanofluids consisting of $\mathrm{Al}_{2} \mathrm{O}_{3}, \mathrm{Al}, \mathrm{Cu}$, and $\mathrm{CuO}$ nanoparticles with sizes of $45,80,80$, and 31 , respectively. The base fluid was transformer oil. The thermal conductivity was studied at 0.5-3\% volume concentration and temperature range of 20$50^{\circ} \mathrm{C}$. The thermal conductivity enhancement for $\mathrm{Al}_{2} \mathrm{O}_{3}$ 
TABLE 9: Enhancement of thermal conductivity.

\begin{tabular}{lcccc}
\hline Author/year & Nanofluid & Particle size $(\mathrm{nm})$ & Concentration (vol\%) & Enhancement ratio \\
\hline Choi et al./2008 [39] & $\mathrm{Cu} /$ transformer oil & 100 & $2.50-7.50$ & $1.12-1.43$ \\
\hline & $\mathrm{Al}_{2} \mathrm{O}_{3}$ (sphere)/pure oil & 13 & $0.5-4.0$ & $1.05-1.21$ \\
Choi et al./2008 [39] & $\mathrm{Al}_{2} \mathrm{O}_{3}$ (fiber)/pure oil & $2 \times 20-200$ & 0.5 & 1.04 \\
& AlN/pure oil & 50 & 0.5 & 1.08 \\
\hline
\end{tabular}

nanofluid was 3-17\% and the conductivity enhancement for $\mathrm{Al}, \mathrm{Cu}$, and $\mathrm{CuO}$ nanofluids was $3.5-24 \%, 5-38 \%$, and 5-26\%, respectively.

Xuan et al. [88] measured thermal conductivity of transformer oil-based nanofluids with $\mathrm{Cu}$ nanoparticles of $100 \mathrm{~nm}$ diameter. The volume concentration was up to $7.5 \%$ at temperature range from 20 to $60^{\circ} \mathrm{C}$. Thermal conductivity enhancement of prepared nanofluids was noted $45 \%$ maximum.

(v) Size and Shape of Nanoparticles. The size of nanoparticles is also an important factor which influences the thermal conductivity of nanofluids. Thermal conductivity increases by decreasing size of nanoparticle. This kind of behaviour is affected by (i) liquid layer formation around nanoparticle and (ii) Brownian motion of nanoparticles. As the size of nanoparticle increases, Brownian motion of nanoparticles reduces due to which heat transfer rate between base liquid and nanoparticle reduces which in turn reduces thermal conductivity. Different researchers $[89,90]$ studied the effect of size on thermal conductivity.

As the different shapes of nanoparticles have different contact area with base fluid, they will have different liquid layer formation and hence different thermal conductivity. The cylindrical nanoparticles showed an increase in thermal conductivity enhancement over the sphere as the aspect ratio of cylindrical nanoparticles is larger and hence there is more contact area between nanoparticle and base fluid. The enhancement of thermal conductivity for cylindrical nanoparticle is caused by a mesh formed by elongated particle that conducts heat through the fluid [91].

(2) Viscosity. Viscosity of oil is a measure of oil resistance to shear. It is commonly known as resistance to flow. A high viscosity indicates high resistance to flow, whereas a low viscosity implies a low resistance to flow. Viscosity of insulating fluid influences the ability to transfer the heat by conduction. Cooling by conduction is the major heat removal mechanism in transformers and higher viscosity would result in higher hot spot temperature within a transformer. The experimental tests have indicated that the viscosity of copper oil-based nanofluids decreases by increasing temperature and increases with the increase of concentration of nanoparticles but it is always high as compared to base oil. Jin [74] measured the viscosity of silica nanofluids with $0.005 \%$ and $0.1 \%$ nanoparticle concentration at a temperature range of $10 \sim 80^{\circ} \mathrm{C}$. The results showed viscosity almost the same as for mineral oil. (a) Factors Affecting Viscosity of Nanofluids. The research studies have manifested that viscosity of nanofluids depends on many parameters such as temperature, volume fraction, shear rate, dispersion method, and shape and size of nanoparticles. In the following section, the experimental studies of different factors affecting viscosity are briefly presented.

(i) Effect of Temperature. The viscosity of nanofluid is influenced by temperature. The experimental results obtained by different researchers [92-94] have concluded that viscosity strongly depends on temperature and viscosity of nanofluid decreases with increase of temperature.

(ii) Volume Fraction of Nanoparticles. The viscosity varies with the variation of nanoparticles concentration. The experimental studies carried out by researchers $[95,96]$ have indicated that the viscosity increases with the increase of nanoparticles concentration.

Fontes et al. [81] measured viscosity of samples prepared with diamond and multiwalled carbon nanotubes (MWCNT) nanoparticles dispersed in transformer oil. The samples were developed for nanoparticles with different concentrations. The results showed that viscosity of nanofluids increases substantially with rise in concentration, achieving 25\% higher than viscosity of pure oil at optimal concentration.

(iii) Effect of Particle Size and Shape. The size and shape of nanoparticles also influence the viscosity of nanofluids. The experimental results obtained by researchers [97, 98] have concluded that viscosity increases by reducing the size of nanoparticles. The shape of nanoparticle also has an effect on the viscosity of nanofluids [85].

(iv) Dispersion Methods. The dispersion methods also affect the viscosity of nanofluids. Different dispersion methods have different effect on viscosity of nanofluids [99]. Moreover, other factors such as sonication time can also influence the viscosity of nanofluids.

(3) Pour Point. The pour point is defined as the temperature of oil at which it becomes semisolid and loses its flow properties. In other words, it is the lowest temperature at which oil still remains pourable (meaning it behaves as a fluid). It is also key factor to characterize the transformer oil. Beheshti et al. [48] characterized all samples with pour point less than $-45^{\circ} \mathrm{C}$.

(4) Flammability-Flame Point and Flash Point. The flammability of transformer fluid is serious safety concern recently. There have been many cases reported of transformer explosion which is hard to extinguish and which can escalate 


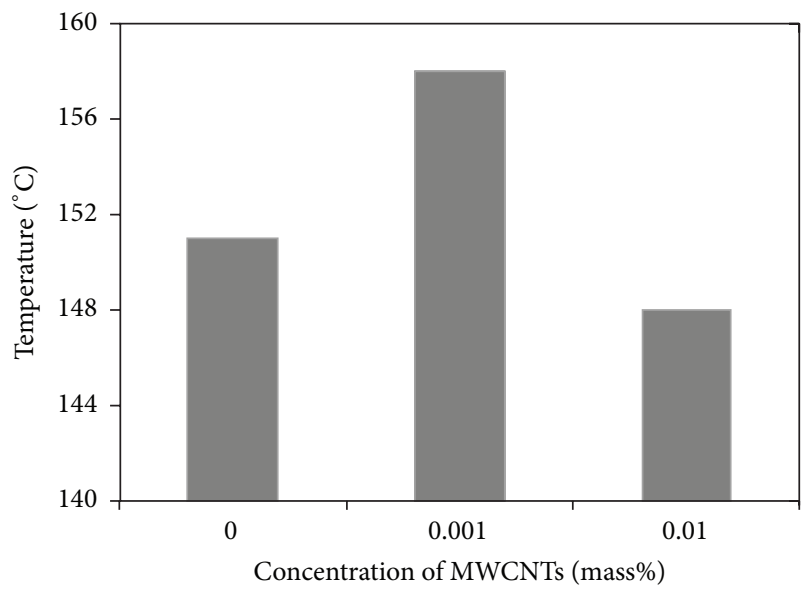

FIGURE 18: Flash point of mineral oil and nanofluids [48].

to the surrounding environment because of oil leaks out. Flash point of a volatile fluid is the lowest temperature at which fluid surface emits enough vapors to form an ignitable mixture in air. The fire point or flame point is the temperature whose vapors continually burn after being ignited. It is the lowest temperature at which, on additional heating beyond the flash point, the sample will sustain a fire for five seconds. Therefore, as the oil is sufficiently heated, it begins to ignite. Flash point is considered as one of the quality indicators to determine the chance of fire hazard. Beheshti et al. [48] measured the flash point with respect to concentration of nanoparticles as shown in Figure 18. The flash point for nanofluid indicated $4.6 \%$ enhancement at concentration (0.001 mass fraction \%) whereas flash point drops with further increase of concentration.

Karthik et al. [40] measured critical parameters of prepared nanofluids. The variation in volume concentration of nanoparticles in transformer oil manifested improvement in viscosity, fire point, and flash point. Breakdown voltage is slightly lower than mineral oil but can be improved by optimum volume concentration and using suitable temperature. The critical parameters of transformer oil can be improved by choosing optimum size and volume concentration of nanoparticles. The detailed result summary is given in Table 10.

2.2.3. Environmental Properties. Environmental safety is usually defined by two basic parameters: biodegradability and low toxicity. The liquids which have high biodegradation rate and show low toxicity are called "environmentally friendly" liquids. These factors are of huge importance when deciding to use the liquids in environmental friendly sensitive areas such as water course to avoid mixing and contamination. The biodegradability indicates the extent of being capable of being slowly broken down into smaller parts and destroyed by natural process in soil or water ways, in case of spillage or leakage. Clearly, it is highly significant that the split liquid disappears fast naturally without applying costly cleanup methods. Transformer oil-based nanofluids are not considered environmental friendly because their spillage to a water course can create serious health problems and environmental issues explained in Section 4.

\section{Research Challenges, Technical Difficulties, and Research Gap}

Although transformer oil-based nanofluids are considered as potential alternate to mineral oil to be used in high-voltage transformers in the future, the problems which limit their use still remain. A rising acknowledgment of performance gains presented by oils mixed with nanoparticles has incited the application of nanofluids in transmission and distribution transformers [38]. A lot of encouraging experimental results have been stated regarding the application of nanofluids; it is not always the case that nanofluids are suitable as electrical insulation and cooling materials $[100,101]$. Also there seems to be certain challenges that have a great room to be further investigated. There seems to be a certain limit of loading levels of nanoparticles that can be suspended into transformer oil, beyond which the electric characteristics will be adversely influenced. This is hugely associated with agglomeration-as the loading level arises, the aggregation of nanoparticles will happen thus leading to negative impact on breakdown performance of nanofluids [100]. The challenges and problems associated with nanofluid research that, we think, all are connected to each other basically are selection of suitable nanoparticles, synthesis of nanofluids, nanoparticle agglomeration, nanoparticle/carrier oil compatibility, and dielectric modification mechanism.

3.1. Research Challenges of Nanofluids. The characteristics of nanofluids depend on multiple factors including the nanoparticle type, method of preparation, type of oil, and resulting combinational properties of nanoparticles and oil. Therefore, it is of utmost importance to be careful in selection of nanoparticles and oil because problems relating to agglomeration of nanoparticles have often been associated with nanoparticle/oil compatibility.

3.1.1. Selection of Nanoparticles. Nanoparticles are a class of materials that exhibit unique chemical and physical characteristics. The selection of nanoparticle which is suitable for improvement of dielectric properties of transformer oil is hugely challenging. Normally, nanoparticles are chosen by looking at their basic properties such as conductivity and permittivity but there is still no way except experiments to know whether a nanoparticle will be useful for dielectric properties improvement or not. Selection of a nanoparticle with a size and volumetric concentration that is suitable for improvement of thermal and insulating properties is also challenging.

3.1.2. Preparation of Nanofluids. The successful application of nanoparticles highly depends upon the synthesis process. The term nanofluid is not simply a liquid-solid mixture. Special requirements including stable suspension, controlled size and concentration, and no chemical change in liquid are needed. Basically, there are two major techniques used 
TABLE 10: Percentage enhancement of critical parameters relative to host oil [40].

\begin{tabular}{|c|c|c|c|c|c|c|}
\hline Nanofluid & $\begin{array}{c}\text { Nanoparticle size } \\
(\mathrm{nm})\end{array}$ & $\begin{array}{l}\text { Enhancement of } \\
\text { flash point }(\%)\end{array}$ & $\begin{array}{l}\text { Enhancement of } \\
\text { flash point }(\%)\end{array}$ & $\begin{array}{c}\text { Enhancement of } \\
\text { BDV after heating } \\
(\%)\end{array}$ & $\begin{array}{l}\text { Enhancement of } \\
\text { viscosity }\left(\text { at } 80^{\circ} \mathrm{C}\right)\end{array}$ & $\begin{array}{c}\text { Enhancement of } \\
\mathrm{pH}(\%)\end{array}$ \\
\hline $\mathrm{Al}_{2} \mathrm{O}_{3} / \mathrm{MO}$ & 0.01 & 17.85 & 12.5 & $31.25(-)$ & 77.86 & 14.32 \\
\hline $\mathrm{Al}_{2} \mathrm{O}_{3} / \mathrm{MO}$ & 0.05 & 14.28 & 6.25 & $12.50(-)$ & 67.37 & 10.63 \\
\hline $\mathrm{Al}_{2} \mathrm{O}_{3} / \mathrm{MO}$ & 0.1 & 14.28 & 12.5 & 3.12 & 51.31 & 10.21 \\
\hline $\mathrm{Al} / \mathrm{MO}$ & 1 & 14.28 & 6.25 & $62.50(-)$ & 62.08 & 7.51 \\
\hline $\mathrm{Al} / \mathrm{MO}$ & 2 & 14.28 & 6.25 & $15.62(-)$ & 34.75 & 86.18 \\
\hline $\mathrm{CuO} / \mathrm{MO}$ & 0.01 & 17.85 & 9.37 & 29.68 & 72.62 & 17.73 \\
\hline $\mathrm{CuO} / \mathrm{MO}$ & 0.05 & 17.85 & 9.37 & 37.50 & 51.31 & 2.26 \\
\hline $\mathrm{CuO} / \mathrm{MO}$ & 0.1 & 17.85 & 9.37 & 46.87 & 34.75 & 4.82 \\
\hline $\mathrm{Cu} / \mathrm{MO}$ & 1 & 21.42 & 12.5 & $9.37(-)$ & 61.96 & 2.55 \\
\hline $\mathrm{Cu} / \mathrm{MO}$ & 2 & 21.42 & 12.5 & 3.12 & 29.01 & 0.85 \\
\hline
\end{tabular}

to develop nanofluids: single-step and two-step technique. Every technique is associated with its pros and cons. The single-step technique is preferable when producing nanofluids containing high-conductivity metals to prevent oxidation. The disadvantage of single-step method is that systems run in batch mode with limited control over most important parameters, including those which control size of nanoparticle. The two-step technique is normally used to produce nanofluids coating oxide nanoparticles and carbon nanotubes. Making nanofluids by using two-step method is challenging because of chances of potential agglomeration of nanoparticles prior to a complete dispersion. At high volume concentration, this problem of agglomeration becomes worse.

3.1.3. Agglomeration of Nanoparticles. The tendency of nanoparticles into larger particles under attractive forces and external stresses may adhere together and develop aggregates of large size which may settle out of suspension because of gravity. Agglomeration means that the particles start to aggregate at a significant rate. The rate of aggregation is generally driven by the frequency of collision and the probability of cohesion during collision. Derjaguin, Verwey, Landau, and Overbeek (DVLO) produced a theory to deal the colloidal stability $[102,103]$. This theory suggests that the stability of a nanoparticle in a nanofluid is determined by the sum of van der Waals attractive forces and electrical double layer repulsion forces which occur between particles as they come close to each other because of Brownian motion. If the attractive force is higher than the repulsive force, the particles will colloid and the suspension is unstable. If the particles have a high repulsive force, the suspension will be stable. The dominant attractive forces between particles and transforming them into larger particles can act as weak points from which a devastating process normally starts, leading to decay of not only electrical characteristics but also thermal properties. For example, the electrical breakdown performance of nanofluid suspended with conducting nanoparticles was found to be negatively affected by the existence of huge agglomerates of nanoparticles [100]. Thermal conductivity was also noted to be influenced by nanoparticle agglomeration [59]. Therefore, appropriate suspension of nanoparticles into transformer oil needs to be achieved to ensure optimized characteristics of the resulting nanofluids. The agglomeration of nanoparticles can be reduced by employing the following methods.

(i) Addition of Surfactants. Surfactants or dispersants are normally used to enhance the stability of nanofluids. The addition of dispersants reduces the surface tension of base liquids and increases the immersion of nanoparticles. Surfactants are chemical compounds applied to nanoparticles in order to decrease the surface tension of fluids and improve the immersion of nanoparticles. Surfactants can distinctly influence the surface properties of a system in small quantity. Dispersants consist of a hydrophilic polar head group and a hydrophobic tail portion, normally long-chain hydrocarbons.

Surfactants are applied to enhance the contact of two materials. Surfactants tend to locate at the interface of the two phases, where it introduces a degree of continuity between liquid and nanoparticles in a two-phase system [104]. The surfactants are used to avoid fast sedimentation; however the exact amount of surfactants should be added to particle for a specific case. Different kinds of surfactants have been used for different types of nanofluids. It is worth noting that this approach may not be used for nanofluids working at elevated temperatures because of probability of bond damaging between nanoparticle and surfactant. In addition, surfactant may raise thermal resistance between base fluids resulting in decline in improvement of thermal conductivity $[84,104]$. The addition of surfactants in the two-phase systems is easy and economic method to improve the stability of nanofluids. The selection of a suitable dispersants is also a major challenge.

(ii) Surface Modification Techniques. This technique is a surfactant-free approach and it uses the functionalized nanoparticles to achieve long-term stability of nanofluids [104]. This technique is used to improve the dispersion of nanoparticles and the compatibility between nanoparticles and liquid materials. Physical or chemical methods are used 
to alter the chemical or physical characteristics and surface structure of nanoparticles. Surface modification plays a vital role to decrease the agglomeration. The surface structure and state of nanoparticle is changed by reaction between modifier and surface of nanoparticle. Due to modifier accumulation or bonding on the surface of nanoparticle, surface force of hydroxyl groups reduces and the hydrogen bonds between nanoparticles are removed to avoid the development of oxygen bridge bonds thereby limiting the happening of agglomeration [105].

(iii) Ultrasonic Agitation. The agglomeration might happen after the preparation of nanofluids over a period of time which results in rapid sedimentation of nanoparticles due to rise of downward body force.

3.1.4. Nanoparticle/Transformer Oil Compatibility. As the nanoparticles are introduced into the base oil, the nanoparticles normally sediment within several minutes because of poor compatibility between the nanoparticles and oil. The agglomerated nanoparticles are constantly settled over time which leads to poor stability and low dielectric performance and low heat-transfer capability of the suspensions.

To address the above mentioned concerns, chemical ways such as coupling agents can be applied to enhance the compatibility between the nanoparticles and the oil. Chemical means normally include special additives that are helpful to isolate nanoparticles. This involves the application of surfactants or dispersants $[106,107]$, which are useful to decrease the surface energy and interfacial tension in nanoparticles. In this regard, dielectric properties of nanofluids have frequently been found to enhance upon nanoparticle surface functionalization. For instance, the AC and impulse breakdown performance of nanofluid containing $\mathrm{TiO}_{2}$ nanoparticles modified by stearic acid was found to be superior to their equivalent nanofluid without surface modification [35]. However, the breakdown performance was, often, not as good as host oil even after surface treatment. More predominantly, the use of different surface modification may result in completely unlikely dielectric performance, a result which is closely connected with processes at nanoparticle/oil interface.

3.1.5. Dielectric Improvement Mechanisms. The mechanism of dielectric improvement of breakdown characteristics of oil is not fully elaborated. George Hwang et al. [24] model can only explain the improvement in insulting strength of oil with $\mathrm{Fe}_{3} \mathrm{O}_{4}$ nanoparticle suspension; it is unable to explain the insulating strength enhancement of semiconductive and insulative nanoparticles suspensions. In the same way, Du's theory [28] has a good explanation for insulating strength improvement for $\mathrm{TiO}_{2}$ nanoparticles suspension but cannot explain the dielectric improvement of $\mathrm{Fe}_{3} \mathrm{O}_{4}$ nanoparticles (or other conductive nanoparticles) suspension. Therefore, it is also a great challenge in nanofluids research to find a mechanism which can explain all nanoparticles insulating strength enhancement and a lot of experimental work is required on this topic.
3.1.6. Other Related Issues. The research studies indicated that relative permittivity, electrical conductivity, and loss factor of developed nanofluids is different from the base oil [27, 47]. The use of prepared nanofluids with these distinct characteristics in the transformers designed with oil specifications will have different electrical stress distribution and therefore have serious complications on transformer structure. Standard testing and maintenance procedure will also be affected. The high cost of transformer oil-based nanofluids will be a huge concern for manufacturers and utilities.

3.2. Technical Difficulties. The main technical difficulties regarding application of nanofluids as insulation liquid in transformers, which need further consideration, are listed as the following [27, 47, 73]:

(i) It will be very hard to apply the nanofluids in existing transformer units because of mismatch of the electrical specifications so it is needed to carry out research regarding use of nanofluids for these excising transformer units.

(ii) More research work is required to find more efficient synthesis methods, to reduce the production cost and identify the potential commercial applications for nanofluids.

(iii) Insulating, dielectric, and thermal improvement benefits offered by nanofluids must be advertised to attract attention from the utilities and manufacturers.

(iv) A huge research work is required to minimize the adverse environmental and human body impacts of transformer oil-based nanofluids.

3.3. Other Problems and Research Gap. Even though transformer oil-based nanofluids manifested extremely attractive characteristics still some crucial problems and challenges exist. The following essential issues must be given thorough attention in future research work. Firstly, more experimental and theoretical work is needed to elaborate the mechanism of improvement of dielectric strength in nanofluids. Until now, there are two theories to explain the improvement in breakdown strength: one can only explain for conductive nanoparticles and the other can only be viable for semiconductive nanoparticles; there is not a single theory/model which can analyze the enhancement of breakdown strength for all types of nanoparticles. Up to now, there is lack of agreement between experimental results of different researchers, so it is essential to carry out more research to find out more about the breakdown mechanisms. The precise and definite formation characterization of the suspensions may be important to describe the inconsistency/discrepancy between the experimental results. Secondly, there is a compatibility problem between oil and nanoparticle, which if not looked up can lead to agglomeration or decrease in breakdown properties. By proper selection of nanoparticle and modification of interface characteristics of two phases could solve the above mentioned problem. Thirdly, the agglomeration of nanoparticles is important issue for both research and practical applications. This problem can be solved by using surface 
modifiers on nanoparticles to a certain extent but still more research is required for long-term stability of nanofluids. Lastly, the shape and size of nanoparticles are important for the characteristics of nanofluids; therefore advanced synthesis techniques will also be an interesting future research work.

\section{Advantages, Disadvantages, and Applications of Nanofluids}

In the following section, the advantages and disadvantages associated with transformer oil-based nanofluids are presented.

4.1. Advantages of Transformer Oil-Based Nanofluids. The advantages of transformer oil-based nanofluids as compared to transformer oil are given as follows:

(i) The transformer oil-based nanofluids have better AC and impulse breakdown performance as compared to the mineral oils so it is favorable to be used in HVAC and HVDC application.

(ii) The AC breakdown strength of transformer oil-based nanofluids is less influenced by moisture as compared to mineral oils so it is helpful in improving insulation life and hence transformer life.

(iii) The transformer oil-based nanofluids have better partial discharge characteristics as compared to the mineral oil.

(iv) The transformer oil-based nanofluids have a better antiaging characteristic as compared to mineral oil so it can improve the operational reliability and lifetime of high voltage transformers.

(v) The transformer oil-based nanofluids have a higher thermal conductivity than the transformer oil and they are helpful in better cooling of transformers.

4.2. Disadvantages of Transformer Oil-Based Nanofluids. The use of nanofluids provides better breakdown performance, partial discharge characteristics, and antiaging properties than transformer oil but still there are some parameters which are limiting their use on large scale in industrial and commercial applications. The introduction of nanofluids in industrial application requires long-term stability, low cost availability, and understanding of the brunt of nanomaterials on human health and environment. In this section an overview of stability of nanofluids and their impact on human health and environment is presented.

(i) Stability of Nanofluids. A nanofluid is called theoretically stable if particle size is smaller than $100 \mathrm{~nm}$ [108]. Nevertheless, it is a huge challenge to keep this size due to existence of attractive forces between nanoparticles, which can lead to agglomeration of nanoparticles. The sedimentation arises in most of the nanofluids due to gravity and the fact that the density of nanoparticles is higher than that of mineral oil.

(ii) Human Health Issues. Nanoparticles have been recognized as one of the major occupational health and safety risks
(OHS) and serious concerns are shown regarding them in various national and international guidelines [109]. The harmfulness of nanomaterials is still ambiguous. Nanoparticles are generally more hazardous as compared to micron sized or bulk materials due to high reactivity of their surface area [110]. The most debated and examined exposure route of nanoparticles to human body is airborne exposure with inhalable uptake. Airborne particles can be categorized by size into three groups: the small particles having an average size smaller than $80 \mathrm{~nm}$, intermediate particles with an average size between $80 \mathrm{~nm}$ and $2000 \mathrm{~nm}$, and large particles with an average size bigger than $2000 \mathrm{~nm}$. The most dangerous particles among these above mentioned particles are intermediate particles because they tend to suspend in air for several weeks whereas small particles are short lived and tend to agglomerate resulting in larger particles and these larger particles are subject to gravitational settling [111]. The one way of infiltration of nanoparticles into human body during inhaling can be through nasal cavity [112, 113]. The exposure of even small amount of nanoparticles can cause serious threat to the health. For example, iron oxide is considered damaging for human lungs [114]. The exposure to copper, chromium, and zinc nanoparticles can cause lung dysfunction and even cancer. There is high risk that some nanoparticle may translocate from respiratory tract and travel to other organs, including central nervous system [111]. The studies indicate that high concentration $\mathrm{ZnO}$ nanoparticle is highly toxic and alumina nanoparticles are moderately toxic and magnetite nanoparticles are slightly toxic [115]. The titania nanoparticles are deadly and can travel to human brain by the odorous neurons during inhaling [116]. The nanoparticle can also have ability to penetrate through skin of by digestion. The risk of penetration through skin is low because of thickness of skin. The nanoparticles, if they penetrate thorough digestive system, can enter into blood stream and accumulate in the liver [117]. Skin and respiratory infections can be caused by carbon and graphite nanoparticles [118]. The necessary precautions should be taken for the worker while preparation of nanofluids to avoid the above mentioned risks.

(iii) Environmental Issues. The nanotechnology poses a serious threat to environment as well. The nanoparticles and their by-products can be released into surrounding atmosphere and water during production, transportation, and preparation. Those nanoparticles would accumulate in water, soil, and plants. The influence of nanoparticles on humans and environment may vary during various stages of their life cycle. The impacts need to be examined for future development by employing Life Cycle Assessment [110]. The potential threat to environment by nanoparticles can be reduced by using efficient way of production, transportation, and preparation.

(iv) High Cost of Nanofluids. The higher manufacturing cost of nanofluids is also one of the reasons that may prevent the use of nanofluids on commercial and industrial level. Both one-step and two-step methods employ expensive, advanced, and state-of-the-art apparatus for preparation of nanofluids which make the nanofluids expensive alternate of transformer oils. 
4.3. Potential Applications of Nanofluids. Transformers need oils with excellent cooling and insulating characteristics. The transformer oil-based nanofluids are offering better insulation and cooling properties as compared to transformer oil and they are being acknowledged in dielectric society as a future alternate liquid insulation for transformers. The transformer oil suspended with conductive nanoparticles reduces the top-oil and hot spot temperature in transformer oil by almost $5^{\circ} \mathrm{C}$ as compared to mineral oil [119]. Moreover, by using the nanofluids, the problems of size and weight of transformer can be reduced because of the excellent dielectric and cooling capabilities [120]. The transmission voltage capacity of transformer can be enhanced by employing nanofluids as liquid insulation. The operational reliability and lifetime of existing transformer units can be enhanced and also failures due to insulation problems can be reduced by applying transformer oil-based nanofluids as liquid insulation instead of mineral oil [3-7].

\section{Conclusion}

Research work on nanofluids as high voltage electrical insulation liquids has been challenging and provides a great room of opportunities for researchers for future research. This paper reviews literature regarding electrical properties, physical properties, environmental properties, challenges, opportunities, pros and cons, and potential applications of transformer oil-based nanofluids. Although many significant features related to nanofluids have been reported however there are many facts which still remain unknown. In this review, an effort was made to demonstrate how nanoparticles can affect the electrical and thermal characteristics of the resulting nanofluids-a more detailed research work on mechanism that we think is required toward the detailed understanding of nanofluids. Nevertheless, more in-depth experimental work on nanofluids is required, and multidisciplinary research collaboration in dealing the challenges is imminent. Lastly, for nanofluid research, there are a lot of challenges and opportunities in the future to come.

\section{Competing Interests}

The authors declare that there is no conflict of interests regarding the publication of this paper.

\section{Acknowledgments}

The authors would like to thank National Natural Science Foundation of China for supporting this research under Contract nos. 51337003, 51472084, and 51477052 and the Fundamental Research Funds for the Central Universities (JB2015019).

\section{References}

[1] M. Rafiq, Y. Z. Lv, Y. Zhou et al., "Use of vegetable oils as transformer oils-a review," Renewable and Sustainable Energy Reviews, vol. 52, pp. 308-324, 2015.
[2] D. Peterchuck and A. Pahwa, "Sensitivity of transformer's hottest-spot and equivalent aging to selected parameters," IEEE Transactions on Power Delivery, vol. 17, no. 4, pp. 996-1001, 2002.

[3] W. H. Bartley, "Investigating transformer failure," in Proceedings of the Weidmann-ACTI 5th Annual Technical Conference on New Diagnostic Concepts for Better Asset Management, November 2006.

[4] EPRI Portfolio 2007-Transmission reliability and performance: 37.002, transformer life extension, http://www.epri.com/ portfolio/.

[5] M. Chiesa and S. K. Das, "Experimental investigation of the dielectric and cooling performance of colloidal suspensions in insulating media," Colloids and Surfaces A: Physicochemical and Engineering Aspects, vol. 335, no. 1-3, pp. 88-97, 2009.

[6] T. O. Rouse, "Mineral insulating oil in transformers," IEEE Electrical Insulation Magazine, vol. 14, no. 3, pp. 6-16, 1998.

[7] L. E. Lundgaard, W. Hansen, D. Linhjell, and T. J. Painter, "Aging of oil-impregnated paper in power transformers," IEEE Transactions on Power Delivery, vol. 19, no. 1, pp. 230-239, 2004.

[8] Y. Xu, S. Qian, Q. Liu, and Z. D. Wang, "Oxidation stability assessment of a vegetable transformer oil under thermal aging," IEEE Transactions on Dielectrics and Electrical Insulation, vol. 21, no. 2, pp. 683-692, 2014.

[9] E. C. Nsofor, "Recent patents on nanofluids (nanoparticles in liquids) heat transfer," Recent Patents on Mechanical Engineering, vol. 1, no. 3, pp. 190-197, 2010.

[10] B. Berkovski and V. Bashtovoy, Magnetic Fluids and Applications Handbook, Begall House, New York, NY, USA, 1996.

[11] R. E. Hebner, "Measurement of electrical breakdown in liquids," in The Liquid State and Its Electrical Properties, vol. 193, pp. 519537, Springer, Boston, Mass, USA, 1989.

[12] S. Choi, "Enhancing thermal conductivity of fluids with nanoparticles," in Developments Applications of Non-Newtonian Flows, D. A. Siginer and H. P. Wang, Eds., FED-Vol. 231/MDVol. 66, pp. 99-105, ASME, New York, NY, USA, 1995.

[13] T. J. Lewis, "Nanometric dielectrics," IEEE Transactions on Dielectrics and Electrical Insulation, vol. 1, no. 5, pp. 812-825, 1994.

[14] Y. Cao, P. C. Irwin, and K. Younsi, "The future of nanodielectrics in the electrical power industry," IEEE Transactions on Dielectrics and Electrical Insulation, vol. 11, no. 5, pp. 797-807, 2004.

[15] X.-Q. Wang and A. S. Mujumdar, "A review on nanofluids-part I: theoretical and numerical investigations," Brazilian Journal of Chemical Engineering, vol. 25, no. 4, pp. 613-630, 2008.

[16] A. K. Singh, "Thermal conductivity of nanofluids," Defence Science Journal, vol. 58, no. 5, pp. 600-607, 2008.

[17] V. Sridhara, B. S. Gowrishankar, C. Snehalatha, and L. N. Satapathy, "Nanofluids-a new promising fluid for cooling," Transactions of the Indian Ceramic Society, vol. 68, no. 1, pp. 1-17, 2015.

[18] G. Paul, M. Chopkar, I. Manna, and P. K. Das, "Techniques for measuring the thermal conductivity of nanofluids: a review," Renewable and Sustainable Energy Reviews, vol. 14, no. 7, pp. 1913-1924, 2010.

[19] L. Godson, B. Raja, D. Mohan Lal, and S. Wongwises, "Enhancement of heat transfer using nanofluids-an overview," Renewable and Sustainable Energy Reviews, vol. 14, no. 2, pp. 629-641, 2010.

[20] V. Segal and K. Raj, "An investigation of power transformer cooling with magnetic fluids," Indian Journal of Engineering \& Materials Sciences, vol. 5, no. 6, pp. 416-422, 1998. 
[21] V. Segal, D. Nattrass, K. Raj, and D. Leonard, "Accelerated thermal aging of petroleum-based ferrofluids," Journal of Magnetism and Magnetic Materials, vol. 201, no. 1-3, pp. 70-72, 1999.

[22] V. Segal, A. Hjortsberg, A. Rabinovich, D. Nattrass, and K. Raj, "AC $(60 \mathrm{~Hz})$ and impulse breakdown strength of a colloidal fluid based on transformer oil and magnetite nanoparticles," in Proceedings of the IEEE International Symposium on Electrical Insulation, pp. 619-622, Arlington, Va, USA, June 1998.

[23] V. Segal, A. Rabinovich, D. Nattrass, K. Raj, and A. Nunes, "Experimental study of magnetic colloidal fluids behavior in power transformers," Journal of Magnetism and Magnetic Materials, vol. 215-216, pp. 513-515, 2000.

[24] J. George Hwang, F. O'Sullivan, M. Zahn, O. Hjortstam, L. A. A. Pettersson, and R. Liu, "Modeling of streamer propagation in transformer oil-based nanofluids," in Proceedings of the Annual Report Conference on Electrical Insulation and Dielectric Phenomena (CEIDP '08), pp. 361-366, Quebec, Canada, October 2008.

[25] J. George Hwang, M. Zahn, F. M. O’Sullivan, L. A. A. Pettersson, O. Hjortstam, and R. Liu, "Electron scavenging by conductive nanoparticles in oil insulated power transformers," in Proceedings of the Electrostatics Joint Conference, June 2009.

[26] J. G. Hwang, M. Zahn, F. M. O’Sullivan, L. A. A. Pettersson, O. Hjortstam, and R. Liu, "Effects of nanoparticle charging on streamer development in transformer oil-based nanofluids," Journal of Applied Physics, vol. 107, no. 1, Article ID 014310, 2010.

[27] P. P. C. Sartoratto, A. V. S. Neto, E. C. D. Lima, A. L. C. Rodrigues de Sá, and P. C. Morais, "Preparation and electrical properties of oil-based magnetic fluids," Journal of Applied Physics, vol. 97, no. 10, Article ID 10Q917, 2005.

[28] Y. Du, Y. Lv, C. Li et al., "Effect of electron shallow trap on breakdown performance of transformer oil-based nanofluids," Journal of Applied Physics, vol. 110, no. 10, Article ID 104104, 2011.

[29] J. Liu, L. Zhou, G. Wu, Y. Zhao, P. Liu, and Q. Peng, “Dielectric frequency response of oil-paper composite insulation modified by nanoparticles," IEEE Transactions on Dielectrics and Electrical Insulation, vol. 19, no. 2, pp. 510-520, 2012.

[30] J. Li, Z. Zhang, P. Zou, S. Grzybowski, and M. Zahn, "Preparation of a vegetable oil-based nanofluid and investigation of its breakdown and dielectric properties," IEEE Electrical Insulation Magazine, vol. 28, no. 5, pp. 43-50, 2012.

[31] M. Hanai, S. Hosomi, H. Kojima, N. Hayakawa, and H. Okubo, "Dependence of $\mathrm{TiO}_{2}$ and $\mathrm{ZnO}$ nanoparticle concentration on electrical insulation characteristics of insulating oil," in Proceedings of the IEEE Conference on Electrical Insulation and Dielectric Phenomena (CEIDP '13), pp. 780-783, Shenzhen, China, October 2013.

[32] M. Rafiq, X. Chen, C. Li et al., "Effect of $\mathrm{Fe}_{3} \mathrm{O}_{4}$ nanoparticle concentrations on insulating property of transformer oil," in Proceedings of the IEEE International Conference on High Voltage Engineering and Application (ICHVE '16), 2016.

[33] W.-X. Sima, X.-F. Cao, Q. Yang, H. Song, and J. Shi, "Preparation of three transformer oil-based nanofluids and comparison of their impulse breakdown characteristics," Nanoscience and Nanotechnology Letters, vol. 6, no. 3, pp. 250-256, 2014.

[34] Z. J. Quan, Y. F. Du, M. T. Chen, C. R. Li, X. X. Li, and Y. Z. Lv, "AC and lighetening breakdown strength of transformer oil modified by semiconducting Nanoparticles," in Proceedings of the IEEE Annual Report Conference on Electrical Insulation and Dielectric Phenomena (CEIDP '11), pp. 652-654, Cancun, Mexico, 2011.
[35] Y.-Z. Lv, X.-X. Li, Y.-F. Du, F.-C. Wang, and C.-R. Li, "Preparation and breakdown strength of $\mathrm{TiO}_{2}$ fluids based on transformer oil," in Proceedings of the Annual Report Conference on Electrical Insulation and Dielectric Phenomena (CEIDP '10), pp. 1-3, IEEE, West Lafayette, Ind, USA, October 2010.

[36] Y. Du, Y. Lv, C. Li et al., "Effect of semiconductive nanoparticles on insulating performances of transformer oil," IEEE Transactions on Dielectrics and Electrical Insulation, vol. 19, no. 3, pp. 770-776, 2012.

[37] T. S. Ramu, B. K. Keshavan, and K. N. Murthy, "Application of a class of nano fluids to improve the loadability of power transformers," in Proceedings of the IEEE 10th International Conference on the Properties and Applications of Dielectric Materials (ICPADM '12), pp. 1-6, Bangalore, India, July 2012.

[38] Y. Lv, Y. Zhou, C. Li, Q. Wang, and B. Qi, "Recent progress in nanofluids based on transformer oil: preparation and electrical insulation properties," IEEE Electrical Insulation Magazine, vol. 30, no. 5, pp. 23-32, 2014.

[39] C. Choi, H. S. Yoo, and J. M. Oh, "Preparation and heat transfer properties of nanoparticle-in-transformer oil dispersions as advanced energy-efficient coolants," Current Applied Physics, vol. 8, no. 6, pp. 710-712, 2008.

[40] R. Karthik, T. S. R. Raja, and R. Madavan, "Enhancement of critical characteristics of transformer oil using nanomaterials," Arabian Journal for Science and Engineering, vol. 38, no. 10, pp. 2725-2733, 2013.

[41] Y. F. Du, Y. Z. Lv, C. R. Li et al., "Effect of water adsorption at nanoparticle-oil interface on charge transport in high humidity transformer oil-based nanofluid," Colloids and Surfaces A: Physicochemical and Engineering Aspects, vol. 415, pp. 153-158, 2012.

[42] H. Jin, T. Andritsch, I. A. Tsekmes, R. Kochetov, P. H. F. Morshuis, and J. J. Smit, "Properties of mineral oil based silica nanofluids," IEEE Transactions on Dielectrics and Electrical Insulation, vol. 21, no. 3, pp. 1100-1108, 2014.

[43] Y.-F. Du, Y.-Z. Lv, J.-Q. Zhou, X.-X. Li, and C.-R. Li, "Breakdown properties of transformer oil-based $\mathrm{TiO}_{2}$ nanofluid," in Proceedings of the Annual Report Conference on Electrical Insulation and Dielectric Phenomena (CEIDP '10), pp. 1-4, West Lafayette, Ind, USA, October 2010.

[44] Y.-F. Du, Y.-Z. Lv, F.-C. Wang, X.-X. Li, and C.-R. Li, "Effect of $\mathrm{TiO}_{2}$ nanoparticles on the breakdown strength of transformer oil," in Proceedings of the Conference Record of the 2010 IEEE International Symposium on Electrical Insulation (ISEI '10), pp. 1-3, IEEE, San Diego, Calif, USA, June 2010.

[45] Y.-Z. Lv, L.-F. Wang, X.-X. Li, Y.-F. Du, J.-Q. Zhou, and C.-R. Li, "Experimental investigation of breakdown strength of mineral oil-based nanofluids," in Proceedings of the IEEE International Conference on Dielectric Liquids (ICDL '11), pp. 1-3, Trondheim, Norway, June 2011.

[46] M. Bakrutheen, R. Karthik, and R. Madavan, "Investigation of critical parameters of insulating mineral oil using semiconductive nanoparticles," in Proceedings of the IEEE International Conference on Circuit, Power and Computing Technologies (ICCPCT '13), pp. 294-299, Nagercoil, India, March 2013.

[47] J. A. Mergos, M. D. Athanassopoulou, T. G. Argyropoulos, and C. T. Dervos, "Dielectric properties of nanopowder dispersions in paraffin oil," IEEE Transactions on Dielectrics and Electrical Insulation, vol. 19, no. 5, pp. 1502-1507, 2012.

[48] A. Beheshti, M. Shanbedi, and S. Z. Heris, "Heat transfer and rheological properties of transformer oil-oxidized MWCNT nanofluid," Journal of Thermal Analysis and Calorimetry, vol. 118, no. 3, pp. 1451-1460, 2014. 
[49] F. O'Sullivan, J. G. Hwang, M. Zahn et al., "A model for the initiation and propagation of positive streamers in transformer oil," in Proceedings of the IEEE International Symposium on Electrical Insulation (ISEI '08), pp. 210-214, British Columbia, Canada, June 2008.

[50] A. S. Ahuja, "Augmentation of heat transport in laminar flow of polystyrene suspensions. I. Experiments and results," Journal of Applied Physics, vol. 46, article 3408, 1975.

[51] E. Kuffel and W. S. Zaeungl, High Voltage Engineering Fundamentals, Pergamon Press, Oxford, UK, 1984.

[52] M. H. Okba, M. H. Saied, M. Z. Mostafa, and T. M. AbdelMoneim, "High voltage direct current transmission-a review, part 1," in Proceedings of the IEEE Energytech, pp. 1-7, Cleveland, Ohio, USA, May 2012.

[53] N. M. Kirby, C. Horwill, and N. M. MacLeod, "Refurbishment strategies for HVDC projects," in Proceedings of the IEEE Power and Energy Society General Meeting (PES '12), pp. 1-6, San Diego, Calif, USA, July 2012.

[54] Y.-F. Du, Y.-Z. Lv, J.-Q. Zhou, M.-T. Chen, X.-X. Li, and C.R. Li, "Effect of ageing on insulating property of mineral Oilbased $\mathrm{TiO}_{2}$ nanofluids," in Proceedings of the IEEE International Conference on Dielectric Liquids (ICDL '11), pp. 1-4, Trondheim, Norway, June 2011.

[55] M.-T. Chen, Y.-F. Du, Y.-Z. Lv, J.-Q. Zhou, X.-X. Li, and C.-R. $\mathrm{Li}$, "Effect of nanoparticles on the dielectric strength of aged transformer oil," in Proceedings of the Annual Report Conference on Electrical Insulation and Dielectric Phenomena (CEIDP '11), pp. 664-667, IEEE, Cancun, Mexico, October 2011.

[56] S. C. Pugazhendhi, "Experimental evaluation on dielectric and thermal characteristics of nano filler added transformer oil," in Proceedings of the International Conference on High Voltage Engineering and Application (ICHVE '12), pp. 207-210, Shanghai, China, September 2012.

[57] D.-E. A. Mansour, E. G. Atiya, R. M. Khattab, and A. M. Azmy, "Effect of titania nanoparticles on the dielectric properties of transformer oil-based nanofluids," in Proceedings of the IEEE Conference on Electrical Insulation and Dielectric Phenomena (CEIDP '12), pp. 295-298, Montreal, Canada, October 2012.

[58] Y. Zhong, Y. Lv, C. Li et al., "Insulating properties and charge characteristics of natural ester fluid modified by $\mathrm{TiO}_{2}$ semiconductive nanoparticles," IEEE Transactions on Dielectrics and Electrical Insulation, vol. 20, no. 1, pp. 135-140, 2013.

[59] Y. Li, J. Zhou, S. Tung, E. Schneider, and S. Xi, "A review on development of nanofluid preparation and characterization," Powder Technology, vol. 196, no. 2, pp. 89-101, 2009.

[60] A. Hays, C. P. Marsh, J. Alvarado, and R. Franks, "The effect of nanoparticleagglomeration on enhanced nanofludic thermal conductivity," in Proceedings of the International Refrigeration and Air Conditioning Conference, Paper 829, West Lafayette, Ind, usa, July 2006.

[61] Y. X. Zhong, Y. Z. Lv, C. R. Li et al., "Insulating properties and charge characteristics of natural ester fluid modified by $\mathrm{TiO}_{2}$ semiconductive nanoparticles," IEEE Transactions on Dielectrics and Electrical Insulation, vol. 20, no. 1, pp. 135-140, 2013.

[62] Y.-X. Zhou, Y.-S. Wang, J.-H. Tian et al., "Breakdown characteristics in transformer oil modified by nanoparticles," High Voltage Engineering, vol. 36, no. 5, pp. 1155-1159, 2010.

[63] R. Liu, L. A. A. Pettersson, T. Auletta, and O. Hjortstam, "Fundamental research on the application of nano dielectrics to transformers," in Proceedings of the Annual Report Conference on Electrical Insulation and Dielectric Phenomena (CEIDP '11), pp. 423-427, Cancun, Mexico, October 2011.
[64] IEC156 International standard, Insulating liquids-Determination of the Breakdown Voltage at Power Frequency-Test Method, 2nd edition, 1995.

[65] O. Kóréh, K. Torkos, M. B. Mahara, J. Borossay, and V. Izvekov, "Study of water clusters in insulating oils by Fourier transform infrared spectroscopy," IEEE Transactions on Dielectrics and Electrical Insulation, vol. 5, no. 6, pp. 896-902, 1998.

[66] B. Du, J. Li, B.-M. Wang, and Z.-T. Zhang, "Preparation and breakdown strength of $\mathrm{Fe}_{3} \mathrm{O}_{4}$ nanofluid based on transformer oil," in Proceedings of the International Conference on High Voltage Engineering and Application (ICHVE '12), pp. 311-313, IEEE, Shanghai, China, September 2012.

[67] H. Jin, T. Andritsch, P. H. F. Morshuis, and J. J. Smit, "AC breakdown voltage and viscosity of mineral oil based fullerene nanofluids," in Proceedings of the IEEE Conference on Electrical Insulation and Dielectric Phenomena (CEIDP '13), pp. 703-706, Shenzhen, China, October 2013.

[68] C. V. Yerin and V. V. Padalka, "Influence of electric field upon the formation of particles cluster in magnetic fluid," Journal of Magnetism and Magnetic Materials, vol. 289, pp. 105-107, 2005.

[69] K. V. Erin, "Electric dipole moments of particle aggregates in magnetite colloidal solutions in liquid dielectrics," Colloid Journal, vol. 70, no. 4, pp. 430-435, 2008.

[70] M. Rajnak, V. I. Petrenko, M. V. Avdeev et al., "Direct observation of electric field induced pattern formation and particle aggregation in ferrofluids," Applied Physics Letters, vol. 107, no. 7, Article ID 073108, 2015.

[71] M. Rajnak, J. Kurimsky, B. Dolnik et al., "Dielectric-spectroscopy approach to ferrofluid nanoparticle clustering induced by an external electric field," Physical Review E, vol. 90, Article ID 032310, 2014.

[72] P. Zou, J. Li, C.-X. Sun, Z.-T. Zhang, and R.-J. Liao, “Dielectric properties and electrodynamic process of natural ester-based insulating nanofluid," Modern Physics Letters B, vol. 25, no. 25, pp. 2021-2031, 2011.

[73] F. Herchl, K. Marton, L. Tomo et al., "Breakdown and partial discharges in magnetic liquids," Journal of Physics Condensed Matter, vol. 20, no. 20, Article ID 204110, 2008.

[74] H. Jin, Dielectric strength and thermal conductivity of mineral oil based nanofluids [M.S. thesis], Delft University of Technology, Delft, The Netherlands, April 2015.

[75] Y. Z. Lv, Y. F. Du, C. R. Li, B. Qi, Y. Zhong, and M. Chen, " $\mathrm{TiO}_{2}$ nanoparticle induced space charge decay in thermal aged transformer oil," Applied Physics Letters, vol. 102, no. 13, Article ID 132902, 2013.

[76] Z.-F. Hu, K.-B. Ma, W. Wang et al., "Thermal aging properties of transformer oil-based $\mathrm{TiO}_{2}$ nanofluids," in Proceedings of the IEEE 18th International Conference on Dielectric Liquids (ICDL '14), pp. 1-4, July 2014.

[77] Y. Z. Lv, Y. F. Du, J. Q. Zhou et al., "Nanoparticle effect on electrical properties of aged mineral oil based nanofluids," in Proceedings of the 7th Annual Canada Conference on Power Systems (CIGRÉ '12), Paris, france, 2012.

[78] D. Li, W. Xie, and W. Fang, "Preparation and properties of copper-oil-based nanofluids," Nanoscale Research Letters, vol. 6, article no. 373, pp. 1-7, 2011.

[79] S. S. Botha, P. Ndungu, and B. J. Bladergroen, "Physicochemical properties of oil-based nanofluids containing hybrid structures of silver nanoparticles supported on silica," Industrial and Engineering Chemistry Research, vol. 50, no. 6, pp. 3071-3077, 2011. 
[80] M. Singh and L. Kundan, "Experimental study on thermal conductivity and viscosity of $\mathrm{Al}_{2} \mathrm{O}_{3}$-nanotransformer oil," International Journal on Theoretical and Applied Research in Mechanical Engineering (IJTARME), vol. 2, no. 3, pp. 125-130, 2013.

[81] D. H. Fontes, G. Ribatski, and E. P. B. Filho, "Experimental evaluation of thermal conductivity, viscosity and breakdown voltage AC of nanofluids of carbon nanotubes and diamond in transformer oil," Diamond \& Related Materials, vol. 58, pp. 115121, 2015.

[82] J. Maxwell, A Treatise on Electricity and Magnetism, Oxford University Press, Oxford, UK, 1873.

[83] Y.-X. Zeng, X.-W. Zhong, Z.-Q. Liu, S. Chen, and N. Li, "Preparation and enhancement of thermal conductivity of heat transfer oil-based $\mathrm{MoS}_{2}$ nanofluids," Journal of Nanomaterials, vol. 2013, Article ID 270490, 6 pages, 2013.

[84] L. Chen, H. Xie, Y. Li, and W. Yu, "Nanofluids containing carbon nanotubes treated by mechanochemical reaction," Thermochimica Acta, vol. 477, no. 1-2, pp. 21-24, 2008.

[85] E. V. Timofeeva, J. L. Routbort, and D. Singh, "Particle shape effects on thermophysical properties of alumina nanofluids," Journal of Applied Physics, vol. 106, Article ID 014304, 2009.

[86] A. M. Gobin, M. H. Lee, N. J. Halas, W. D. James, R. A. Drezek, and J. L. West, "Near-infrared resonant nanoshells for combined optical imaging and photothermal cancer therapy," Nano Letters, vol. 7, no. 7, pp. 1929-1934, 2007.

[87] H. E. Patel, T. Sundararajan, and S. K. Das, "An experimental investigation into the thermal conductivity enhancement in oxide and metallic nanofluids," Journal of Nanoparticle Research, vol. 12, no. 3, pp. 1015-1031, 2010.

[88] Y. Xuan, Q. Li, and W. Hu, "Aggregation structure and thermal conductivity of nanofluids," AIChE Journal, vol. 49, no. 4, pp. 1038-1043, 2003.

[89] I. Chopkar, S. Sudarshan, P. K. Das, and I. Manna, "Effect of particle size on thermal conductivity of nanofluid," Metallurgical and Materials Transactions A: Physical Metallurgy and Materials Science, vol. 39, no. 7, pp. 1535-1542, 2008.

[90] J. A. Eastman, S. U. S. Choi, S. Li, W. Yu, and L. J. Thompson, "Anomalously increased effective thermal conductivities of ethylene glycol-based nanofluids containing copper nanoparticles," Applied Physics Letters, vol. 78, no. 6, pp. 718-720, 2001.

[91] H. Xie, J. Wang, T. Xi, and Y. Liu, "Thermal conductivity of suspensions containing nanosized $\mathrm{SiC}$ particles," International Journal of Thermophysics, vol. 23, no. 2, pp. 571-580, 2002.

[92] C. T. Nguyen, F. Desgranges, N. Galanis et al., "Viscosity data for $\mathrm{Al}_{2} \mathrm{O}_{3}$-water nanofluid-hysteresis: is heat transfer enhancement using nanofluids reliable?" International Journal of Thermal Sciences, vol. 47, no. 2, pp. 103-111, 2008.

[93] M. Kole and T. K. Dey, "Role of interfacial layer and clustering on the effective thermal conductivity of $\mathrm{CuO}$-gear oil nanofluids," Experimental Thermal and Fluid Science, vol. 35, no. 7, pp. 1490-1495, 2011.

[94] P. K. Namburu, D. P. Kulkarni, A. Dandekar, and D. K. Das, "Experimental investigation of viscosity and specific heat of silicon dioxide nanofluids," IET Micro \& Nano Letters, vol. 2, no. 3, pp. 67-71, 2007.

[95] K. B. Anoop, S. Kabelac, T. Sundararajan, and S. K. Das, "Rheological and flow characteristics of nanofluids: influence of electroviscous effects and particle agglomeration," Journal of Applied Physics, vol. 106, no. 3, 2009.

[96] N. Putra, W. Roetzel, and S. K. Das, "Natural convection of nano-fluids," Heat and Mass Transfer, vol. 39, no. 8, pp. 775-784, 2003.
[97] J. Chevalier, O. Tillement, and F. Ayela, "Rheological properties of nanofluids flowing through microchannels," Applied Physics Letters, vol. 91, Article ID 233103, 2007.

[98] M. J. Pastoriza-Gallego, C. Casanova, J. L. Legido, and M. M. Piñeiro, "CuO in water nanofluid: influence of particle size and polydispersity on volumetric behaviour and viscosity," Fluid Phase Equilibria, vol. 300, no. 1-2, pp. 188-196, 2011.

[99] X. Wang, X. Xu, and S. U. S. Choi, "Thermal conductivity of nanoparticle-fluid mixture," Journal of Thermophysics and Heat Transfer, vol. 13, no. 4, pp. 474-480, 1999.

[100] J. Kudelcik, P. Bury, P. Kopcansky, and M. Timko, "Dielectric breakdown in mineral oil ITO 100 based magnetic fluid," Physics Procedia, vol. 9, pp. 78-81, 2010.

[101] A. Józefczak, "Study of low concentrated ionic ferrrofluid stability in magnetic field by ultrasound spectroscopy," Journal of Magnetism and Magnetic Materials, vol. 321, no. 14, pp. 22252231, 2009.

[102] T. Missana and A. Adell, "On the applicability of DLVO theory to the prediction of clay colloids stability," Journal of Colloid and Interface Science, vol. 230, no. 1, pp. 150-156, 2000.

[103] I. Popa, G. Gillies, G. Papastavrou, and M. Borkovec, "Attractive and repulsive electrostatic forces between positively charged latex particles in the presence of anionic linear polyelectrolytes," Journal of Physical Chemistry B, vol. 114, no. 9, pp. 3170-3177, 2010.

[104] W. Yu and H. Xie, "A review on nanofluids: preparation, stability mechanisms, and applications," Journal of Nanomaterials, vol. 2012, Article ID 435873, 17 pages, 2012.

[105] L. S. Wang and R. Y. Hong, "Synthesis, surface modification and characterization of nanoparticles," in Advances in Nanocomposites-Synthesis, Characterization and Industrial Applications, pp. 289-323, 2011.

[106] Y.-Z. Lü, S.-N. Zhang, Y.-F. Du, M.-T. Chen, and C.-R. Li, "Effect of oleic acid surface modification on dispersibility of $\mathrm{TiO}_{2}$ nanoparticles in transformer oils," Journal of Inorganic Materials, vol. 28, no. 6, pp. 594-598, 2013.

[107] W. R. Viali, G. B. Alcantara, P. P. C. Sartoratto et al., "Investigation of the molecular surface coating on the stability of insulating magnetic oils," The Journal of Physical Chemistry C, vol. 114, no. 1, pp. 179-188, 2010.

[108] S. K. Das, S. U. S. Choi, W. Yu, and T. Pradeep, Nanofluids: Science and Technology, Wiley-Interscience, New York, NY, USA, 2008.

[109] E. Rial-González, S. Copsey, P. Paoli, and E. Schneider, Priorities for Occupational Safety and Health Research in the EU-25, European Agency for Safety and Health at Work, Strassen, Luxembourg, 2005.

[110] P. Krajnik, F. Pusavec, and A. Rashid, "Nanofluids: properties, applications and sustainability aspects in materials processing technologies," in Advances in Sustainable Manufacturing: Proceedings of the 8th Global Conference on Sustainable Manufacturing, pp. 107-113, Springer, Berlin, Germany, 2011.

[111] R. Kochetov, P. H. F. Morshuis, J. J. Smit, T. Andritsch, and A. Krivda, "Precautionary remarks regarding synthesis of nanocomposites," in Proceedings of the 32nd Electrical Insulation Conference (EIC '14), pp. 51-54, IEEE, Philadelphia, Pa, USA, June 2014.

[112] A. Nemmar, P. H. M. Hoet, B. Vanquickenborne et al., "Passage of inhaled particles into the blood circulation in humans," Circulation, vol. 105, no. 4, pp. 411-414, 2002. 
[113] M. Geiser, B. Rothen-Rutishauser, N. Kapp et al., "Ultrafine particles cross cellular membranes by nonphagocytic mechanisms in lungs and in cultured cells," Environmental Health Perspectives, vol. 113, no. 11, pp. 1555-1560, 2005.

[114] J. W. Sutherland, V. N. Kulur, and N. C. King, "An experimental investigation of air quality in wet and dry turning," CIRP Annals-Manufacturing Technology, vol. 49, no. 1, pp. 61-64, 2000.

[115] H. A. Jeng and J. Swanson, "Toxicity of metal oxide nanoparticles in mammalian cells," Journal of Environmental Science and Health, vol. 41, no. 12, pp. 2699-2711, 2006.

[116] J. Wang, Y. Liu, F. Jiao et al., “Time-dependent translocation and potential impairment on central nervous system by intranasally instilled $\mathrm{TiO}_{2}$ nanoparticles," Toxicology, vol. 254, no. 1-2, pp. 82-90, 2008.

[117] B. Baroli, M. G. Ennas, F. Loffredo, M. Isola, R. Pinna, and M. A. López-Quintela, "Penetration of metallic nanoparticles in human full-thickness skin," Journal of Investigative Dermatology, vol. 127, no. 7, pp. 1701-1712, 2007.

[118] R. H. Hurt, M. Monthioux, and A. Kane, "Toxicology of carbon nanomaterials: status, trends, and perspectives on the special issue," Carbon, vol. 44, no. 6, pp. 1028-1033, 2006.

[119] G.-Y. Jeong, S. P. Jang, H.-Y. Lee, J.-C. Lee, S. Choi, and S.H. Lee, "Magnetic-thermal-fluidic analysis for cooling performance of magnetic nanofluids comparing with transformer oil and air by using fully coupled finite element method," IEEE Transactions on Magnetics, vol. 49, no. 5, pp. 1865-1868, 2013.

[120] L. P. Danescu, A. M. Morega, M. Morega et al., "Prototyping a ferrofluid-cooled transformer," IEEE Transactions on Industry Applications, vol. 49, no. 3, pp. 1289-1298, 2013. 



\section{Hindawi}

Submit your manuscripts at

http://www.hindawi.com

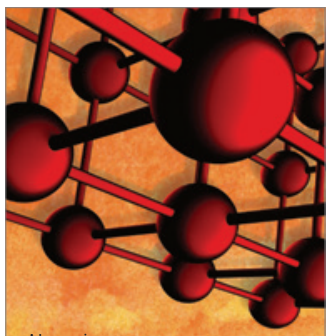

Materials Science and Engineering
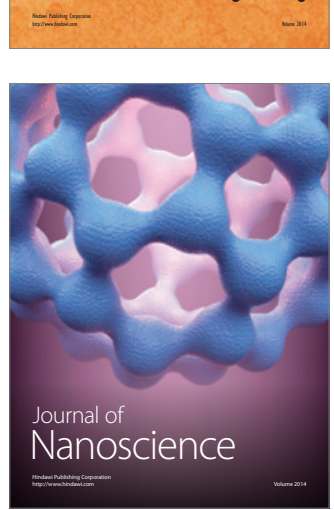
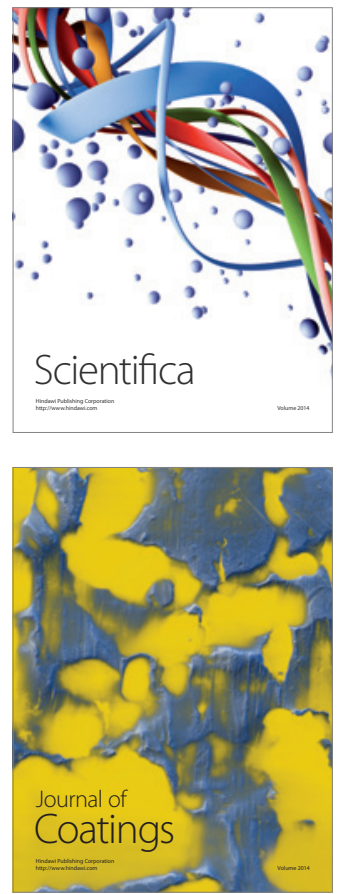
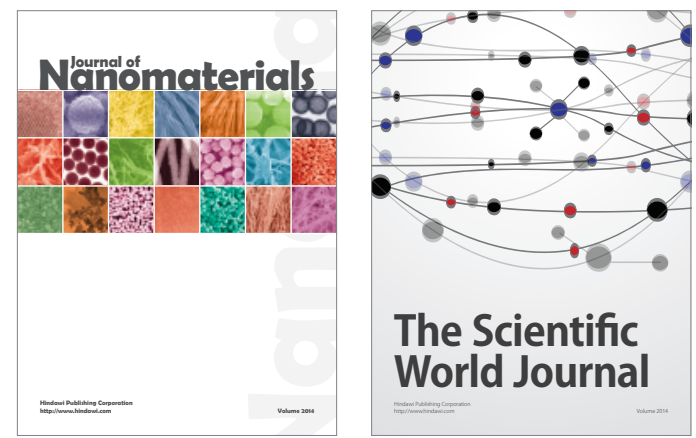

The Scientific World Journal
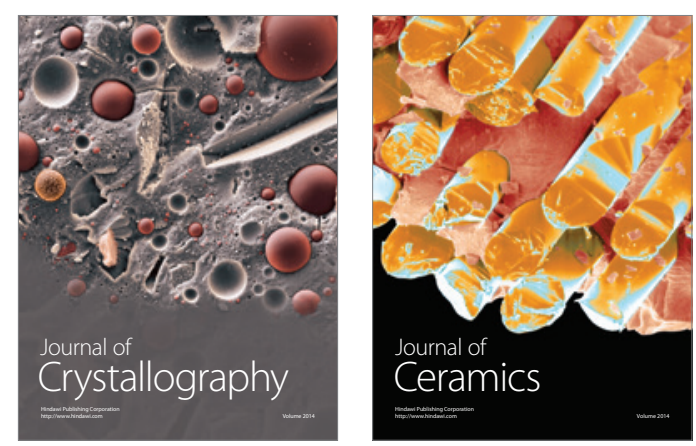
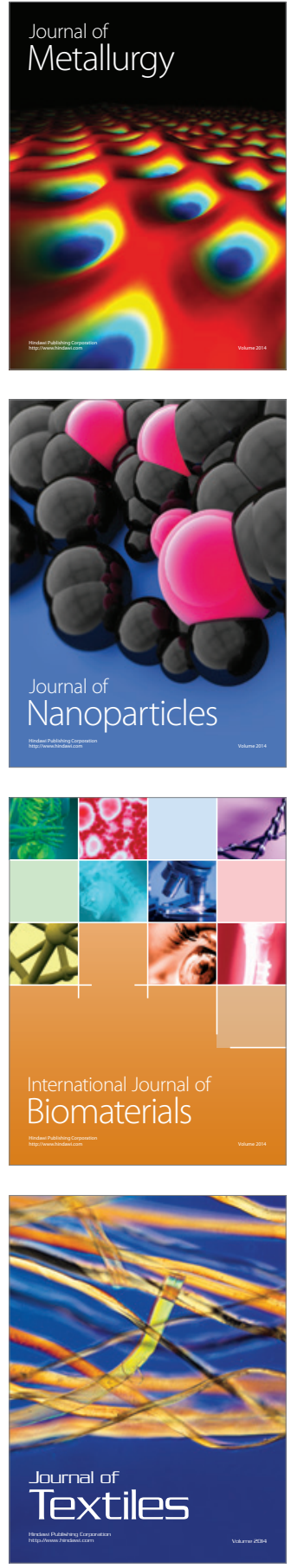